\title{
Estudio cortical del Pirineo mediante refracción y reflexión de gran ángulo utilizando terremotos como fuente sísmica natural
}

\author{
Amanda Antonio-Vigil(1), Mario Ruiz(2), Jorge Gallasteguii ${ }^{(1)}$, Jordi Díaz ${ }^{(2)}$ y Josep Gallart ${ }^{(2)}$ \\ (1) Departamento de Geología, Universidad de Oviedo, c/ Jesús Arias de Velasco s/n., 3005 Oviedo, España. \\ amandaantoniovigil@gmail.com, jorge@geol.uniovi.es \\ (2) Departamento de Estructura y Dinámica de laTierra, Instituto de Ciencias de la Tierra, Jaume Almera, \\ ICTJA-CSIC, Lluís Solé i Sabarís s/n., 08028 Barcelona, España.
}

mruiz@ictja.csic.es

\begin{abstract}
RESUMEN
En este trabajo se analizan tres perfiles sísmicos de refracción y reflexión de gran ángulo registrados en los Pirineos con el fin de aportar nuevos conocimientos sobre su estructura cortical. Se emplearon como fuente sísmica varios terremotos de magnitud superior a 2.5 ocurridos en las proximidades de las líneas a estudiar. Se demuestra la viabilidad de utilizar sismicidad natural como fuente sísmica para la realización de perfiles de gran ángulo, lo que permite aprovechar despliegues dispuestos con otros objetivos. Se analizarán dos perfiles localizados en el Pirineo oriental (Cataluña) con direcciones N-S y E-O, y un tercero en el Pirineo occidental (Navarra) con dirección NE-SO, desplegados inicialmente para el registro de telesísmos y el análisis de funciones receptoras. Los perfiles adquiridos en el sector oriental del Pirineo permitieron acotar el techo de la corteza inferior a $20 \mathrm{~km}$ de profundidad. El perfil E-O muestra, en su extremo más oriental, el Moho como una rampa ascendente hacia el este, pasando de los $35-40 \mathrm{~km}$ de profundidad en la zona central del perfil a $25 \mathrm{~km}$ en su extremo oriental. El perfil de Navarra permitió acotar con gran detalle la estructura cortical del extremo occidental del Pirineo. El modelo obtenido muestra la indentación de la corteza inferior y media Europea en la corteza Ibérica. El Moho Europeo aparece a $30 \mathrm{~km}$ de profundidad en la zona central, mientras que el Moho Ibérico muestra una rampa buzante hacia el norte, llegando hasta a los $45-50 \mathrm{~km}$ de profundidad en su extremo más septentrional.
\end{abstract}

Palabras clave: geofísica, Pirineos, sísmica de refracción y reflexión de gran ángulo, sismicidad.

\section{Crustal study of the Pyrenees by refraction and wide-angle reflection using earthquakes as a natural seismic source}

\begin{abstract}
In this study we analyse three wide-angle seismic profiles in the Pyrenees to provide new insights into their crustal structure. Several earthquakes with magnitudes greater than 2.5 that occurred in the vicinity of the analysed profiles have been used as the seismic source. We demonstrate the feasibility of using natural seismicity as the seismic source, which would allow using deployments of seismic stations designed for other objectives. We have analysed a total of three profiles in this study, two of them being located in the eastern Pyrenees (Cataluña) with N-S and E-O directions, and the third in the western Pyrenees (Navarra) with NE-SO orientation. All of them were originally deployed to record teleseisms for receiver function analysis. Profiles in the eastern Pyrenean edge constrain the top of the lower crust at a depth of $20 \mathrm{~km}$. In the easternmost sector of the E-W profile, Moho has been imaged as an eastward rising ramp, with a depth decreasing from 35$40 \mathrm{~km}$ in the middle of the profile to a depth of $25 \mathrm{~km}$ in the eastern edge. The Navarra profile allowed us to constrain the crustal structure of the western Pyrenean edge in detail. The obtained model allowed the imaging of the mid-lower crustal indentation between the Iberian and European plates. The European Moho has been constrained at a depth of $30 \mathrm{~km}$ in a small region of the central part of the model, whereas the Iberian Moho has been imaged in its northernmost edge dipping northwards to a depth of 45-50 km.
\end{abstract}

Keywords: geophysics, Pyrenees, refraction and wide-angle reflection, seismicity. 


\section{ABRIDGED ENGLISH VERSION}

Acquisition of refraction and wide-angle seismic reflection profiles is commonly done by using controlled blasts as seismic source, where position and origin time are known with absolute precision. This study shows the viability of using natural seismicity, i.e. local earthquakes, as the seismic source to obtain refraction and wide-angle reflection profiles. This allows us to take advantage of seismic deployments designed for other objectives and thus obtain complementary information of the crustal structure.

Three refraction and wide-angle reflection profiles along the Pyrenees have been modelled, two in the eastern Pyrenean edge (profiles Cataluña 1 and 2, E-W and N-S oriented) and one in the western edge (profile Navarra NE-SW oriented). We have used seismic records of six local earthquakes which occurred during 2013 and 2015. These earthquakes, with magnitudes higher than 2.5, were located close to three transects deployed during the Pyrope project, originally designed to record teleseisms and obtain receiver functions.

The first task of this study was to precisely relocate the seismic events, using seismic records from both permanent stations (IGN, IGCG and RéNaSS) and Pyrope Project temporary networks. The objective was to minimize the hypocentral location errors, but also to accurately calculate the exact time when the events occurred. Event picking was done manually using SAC program, and relocations were obtained using Hypo71 and HypoEllipse programs.

For each event and each profile, a record-section was obtained using the final relocalizations of the events. Modelling of the seismic phases recorded on each profile was done using the ray tracing package Rayinver and applying the forward modelling or trial and error method, to adjust the travel time of each phase identified on every record-section. All the available bibliographic information was compiled and used, not only to constrain areas of the models poorly covered by the data, but also to validate the results.

Models obtained in the eastern Pyrenean edge (Cataluña 1 and 2) show a simplified crustal structure where it is not possible to differentiate between upper and middle crust due to the geometry of the profile and the relative location of the natural seismic sources (earthquakes). The top of the lower crust has been constrained at a depth of $20 \mathrm{~km}$. We were also able to model in the profile Cataluña 1 (E-W) segments of the top of the lower crust and Moho surfaces. The aperture of Cataluña $2(\mathrm{~N}-\mathrm{S})$ is not wide enough to record deep phases related to the Moho and only the top of the lower crust is well constrained. Morphology and Moho depths obtained in the easternmost sector of the E-W profile are in agreement with models proposed by other authors, compiled by Díaz et al. 2016, and also models obtained in recent receiver functions studies over the same E-W profile (Díaz et al., 2018). Furthermore, the top of the lower crust obtained in this sector of the study area can be correlated with high precision with an intracrustal converter identified in the receiver functions by Díaz et al. (2018).

The Navarra profile is sub-parallel to Pamplona Fault and oblique to the orogen and provides a great deal of information, allowing us to constrain the crustal structure of the western Pyrenean edge. The model obtained shows the Ebro and Arzacq basins, and it is possible to differentiate between the upper and middle crusts, including the mid-lower crustal indentation between the Iberian and European plates. The European Moho has been constrained at a depth of $30 \mathrm{~km}$ in a small region of the central part of the model, whereas the Iberian Moho has been imaged in its northernmost edge dipping northwards to a depth of 45-50 km. In both cases, these results complement and agree with previous models, without taking into account mantle intrusions to high levels of the crust published by other authors in this area, showing the crustal thickening produced by the collision of both plates.

\section{Introducción}

Conocer la estructura cortical de una región es importante para llegar a comprender el comportamiento geodinámico y evolutivo de la misma. Los estudios geofísicos basados en datos sísmicos proporcionan información profunda que permiten caracterizar esta estructura. El desarrollo de este tipo de estudios fue notable a partir de los años 70 debido, principalmente, a la gran demanda de recursos naturales, así como a los importantes avances en las técnicas de exploración e instrumentación.

A lo largo de las últimas décadas de los siglos $X X$ y $X X I$, los Pirineos han sido objeto de numerosos estudios de sísmica de refracción y reflexión de gran ángulo destinados a obtener imágenes de la estructura cortical de la zona de colisión entre la placa Ibérica y la placa Europea.

En el presente trabajo se utilizaron los datos registrados en tres de las transectas desplegadas originalmente en el marco del proyecto Pyrope (Pyrenean Observational Portable Experiment) (Chevrot et al., 2018), en colaboración con el proyecto Misterios, cuyo objetivo principal era recopilar información sísmica que permitiese mejorar la comprensión de las estructuras profundas, cómo se formaron las principales estructuras geológicas (Pirineos y golfo de Vizcaya), aclarar la geometría de las fallas activas y 
mejorar la precisión de la localización de los terremotos.

El objetivo de este estudio es analizar y modelizar tres perfiles sísmicos de gran ángulo a lo largo de los Pirineos: dos de ellos en el Pirineo oriental (perfiles Cataluña) con direcciones N-S y E-O, y un tercero en el Pirineo occidental (perfil Navarra) con dirección NE-SO. Los dos perfiles de Cataluña, perpendiculares entre sí, van de la Seu d'Urgell a Cap de Creus el E-O y de Manresa a Carcasona (Francia) el N-S con una extensión de $152 \mathrm{~km}$ y $180 \mathrm{~km}$ respectivamente. El perfil de Navarra tiene una extensión de $225 \mathrm{~km}$ desde el $\mathrm{S}$ de Pamplona al $\mathrm{N}$ de Mont de Marsan (Francia) (Fig. 1).
Se pretende con ello aportar nuevos conocimientos sobre la estructura cortical y evolución geodinámica de los Pirineos y comprobar la viabilidad de utilizar sismicidad natural como fuente de energía para la realización de los perfiles, lo que permitiría aprovechar despliegues de estaciones sísmicas dispuestos con otros objetivos y obtener datos sobre la estructura cortical complementarios a los perseguidos.

La realización de perfiles de gran ángulo en tierra suele llevarse a cabo empleando explosivos dispuestos en pozos, sabiéndose con precisión tanto la posición de la fuente como la hora de origen de la detonación. Sin embargo, la peculiaridad de este estudio radica en que, como fuente sísmica se emplearon

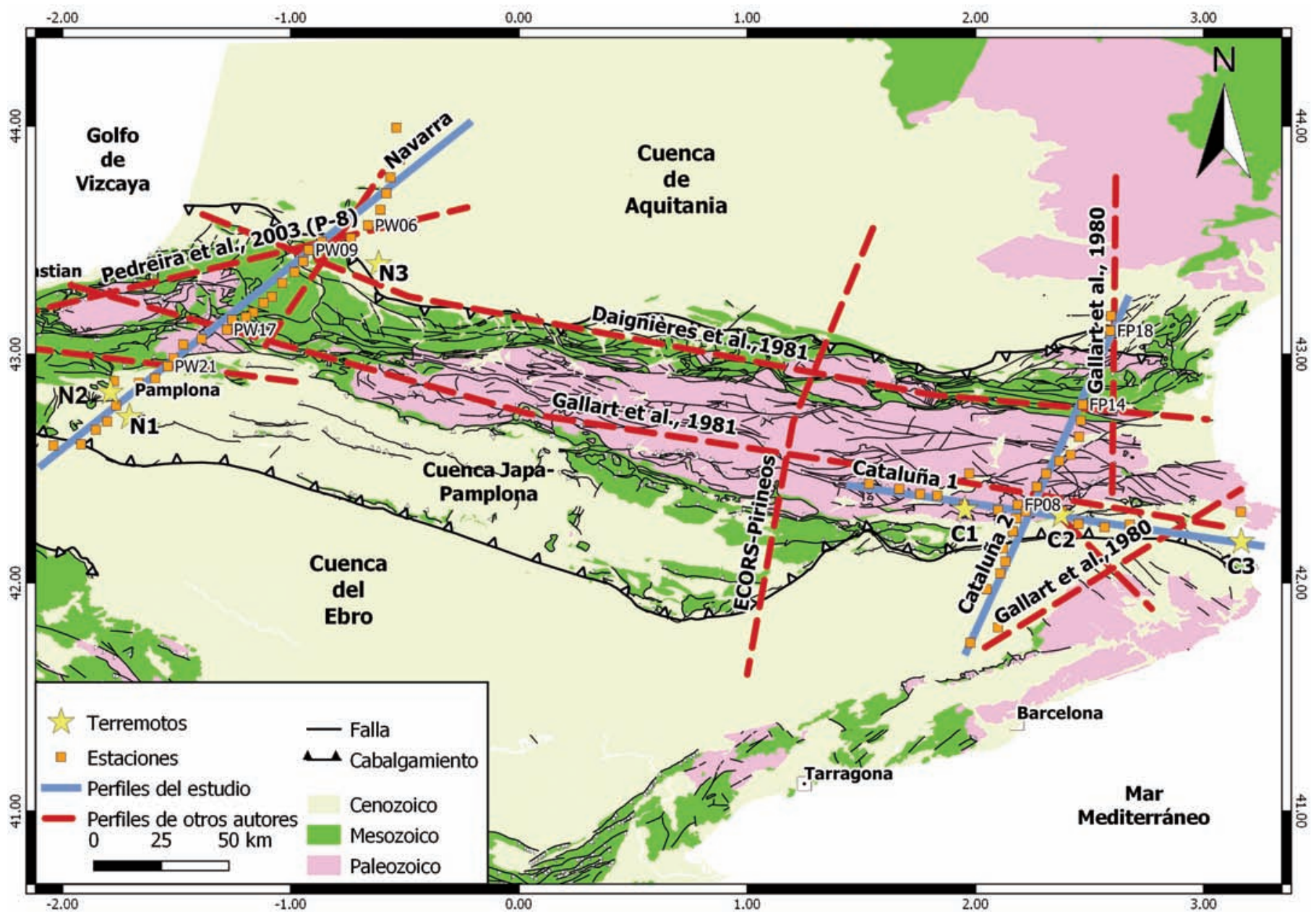

Figura 1. Mapa geológico de los Pirineos con las principales estructuras del orógeno y edades de los materiales. Se han representado los diferentes perfiles sísmicos previos realizados en la zona (líneas rojas discontinuas), los perfiles de gran ángulo interpretados en este trabajo (líneas azules continuas) a partir de los datos de las estaciones Pyrope (cuadrados naranjas) y los terremotos que se han empleado como fuente símica en este estudio (estrellas amarillas).

Figure 1. Geological map of the Pyrenees with the ages and main structures of the orogen, Previous seismic profiles carried out in the area (discontinuous red lines), wide-angle profiles interpreted in this work (continuous blue lines) using the data from Pyrope stations (orange squares) and earthquakes used as seismic sources (yellow stars) are shown. 
varios terremotos de magnitud superior a 2.5 ocurridos en los años 2013-2015 en las proximidades de las líneas a estudiar, por lo que no se dispone de dos parámetros críticos, la posición exacta de la fuente y el tiempo origen. Dichos parámetros deberán ser analizados y determinados con la mayor precisión posible antes de empezar a modelizar, ya que los errores en la localización de las fuentes y su tiempo de inicio pueden repercutir en fallos en la distribución de velocidad-profundidad de las capas del modelo (Zelt, 1999).

Se relocalizaron de forma precisa los hipocentros de todos los terremotos empleados en este trabajo, generando una base de datos que incluyera tanto los sismogramas de las estaciones permanentes más cercanas, Instituto Cartográfico y Geológico de Cataluña (ICGC) (ICGC, 2000), Instituto Geográfico Nacional (IGN) y la red francesa de los Pirineos "Réseau National de Surveillance Sismique" (RéNaSS) (RESIF, 1995), como de las estaciones temporales desplegadas en el proyecto Pyrope. Posteriormente, se realizaron lecturas precisas de las primeras llegadas de las ondas $\mathrm{P}$ y $\mathrm{S}$ a cada una de las estaciones con el programa informático $S A C$ (Seismic Analysis Code) (Goldstein y Minner, 1996; Goldstein et al., 2003). Con los tiempos de llegada obtenidos se realizaron varias pruebas de localización empleando los programas Hypo71 (Lee y Lahr, 1975) y HypoEllipse (Lahr, 1999; Lahr y Snoke, 2003). Una vez se obtuvieron las localizaciones finales de los eventos se construyeron los ensamblajes (Record Sections) asociados a cada uno de los terremotos estudiados en cada línea, procediendo a la identificación de las distintas fases, asociadas a refracciones o reflexiones en las distintas capas de la corteza. Se reflejaron en sus incertidumbres los posibles efectos de los errores de la localización de las fuentes, a fin de tenerlos en cuenta y propagarlos en la modelización. En este trabajo, se ha optado por el método directo para la modelización de los perfiles empleándose para ello el paquete informático Rayinvr (Zelt y Ellis, 1988; Zelt y Smith, 1992). Durante los procesos de ajuste de los modelos se ha tenido en cuenta toda la información bibliográfica disponible a fin de complementar aquellas zonas para las que no se disponía de datos suficientes y poder así contrastar los resultados obtenidos con los precedentes y reducir el grado de subjetividad de este método. La introducción de resultados previos en el modelo inicial, y el hecho de usarlos como puntos de control a lo largo de la modelización, ayuda especialmente en las zonas estructuralmente muy complejas y/o en las que se tienen pocos datos o éstos son muy dispersos (Zelt, 1999).
Hay que hacer constar que el método empleado tiene algunas limitaciones. En primer lugar, la resolución del modelo y la profundidad de penetración alcanzada dependen respectivamente, del espaciado de las estaciones sísmicas y fuentes, y la longitud total de la línea. En este caso, al aprovechar perfiles con geometrías diseñadas para registrar telesismos y generar funciones receptoras, puede que la geometría no sea la óptima para realizar perfiles de gran ángulo al no tener una apertura lo suficientemente grande como para registrar fases muy profundas, ni un espaciado óptimo para resolverlas lateralmente, dificultando su identificación. Una mayor resolución lateral de las fases permitiría obtener imágenes de detalle de la topografía de las superficies reflectoras (Palomeras et al., 2009). A fin de aumentar los offsets de los perfiles se han incluido, siempre que ha sido posible, las trazas de las estaciones permanentes alineadas con la red temporal. Por otro lado, al haberse empleado en este trabajo terremotos como fuente sísmica, no se puede controlar su posición respecto a la red sísmica desplegada ni su magnitud, lo cual puede ser también un factor limitante para la obtención de resultados. En el proceso de modelización no se ha corregido el hecho de que algunos de los terremotos estuviesen fuera de la línea del perfil, ya que, una vez proyectadas sobre la línea habría que corregir sus tiempos de propagación y, para ello, sería necesario conocer a priori el modelo de velocidades objeto de estudio. Por tanto, los ajustes, sobre todo de las primeras llegadas de las estaciones más cercanas, estarán afectados en mayor o menor medida por este fenómeno, dando lugar a pequeños desajustes y los valores velocidad/profundidad obtenidos se verán parcialmente afectados.

\section{Contexto geológico}

La zona de estudio está situada en el NE de la península lbérica y comprende tanto la vertiente $\mathrm{N}$ como $\mathrm{S}$ de la cordillera pirenaica. Los Pirineos son un orógeno de colisión de dimensiones moderadas que ha sido el resultado de la superposición de dos orogenias, la Varisca europea y la Alpina, separadas por un importante periodo de extensión cortical durante el Mesozoico. La cadena Varisca formada durante el Carbonífero aflora en varios macizos, entre los que se encuentra la Zona Axial paleozoica, que posteriormente sufrió una nueva deformación debido a la orogenia Alpina (De Sitter, 1956; Matte, 1991).

En el ciclo alpino, por su parte, puede diferenciarse una primera etapa extensional seguida de una etapa compresiva. La etapa extensional abarca desde 
el Pérmico Superior al inicio del Cretácico Superior y en ella se individualizan la microplaca lbérica y la placa Euroasiática, como resultado de la apertura del océano Atlántico y del golfo de Vizcaya. Durante la etapa compresiva, que abarca desde el Cretácico Superior hasta el Mioceno Medio, se produjo la colisión entre la microplaca lbérica y la placa Euroasiática, lo que genera las cadenas alpinas, como la cordillera Pirenaico-Cantábrica, la cordillera Ibérica, el Sistema Central y las Béticas y sus respectivas cuencas de antepaís.

Geológicamente se pueden dividir en tres zonas: la Zona Norpirenaica, la Zona Surpirenaica y la Zona Axial (Mattauer, 1968).

La Zona Norpirenaica está formada por una franja de unos $30 \mathrm{~km}$ de anchura dominada por cabalgamientos alpinos dirigidos hacia el $\mathrm{N}$ de tipo thick-skinned, desarrollados entre el Cretácico Superior y el Eoceno Superior u Oligoceno Inferior y que incluyen rocas del Paleozoico deformadas en la orogenia Varisca y rocas mesozoico-terciarias de la cobertera (Fischer, 1984; Teixell, 1998). Muchos de los cabalgamientos alpinos son el resultado de una inversión tectónica de fallas extensionales mesozoicas previas. EI límite $\mathrm{N}$ de la Zona Norpirenaica se sitúa en el cabalgamiento frontal Norpirenaico mientras que el límite $\mathrm{S}$ coincide con la traza de la falla Norpirenaica (FNP), de orientación E-O. La FNP es una estructura profunda que termina hacia el oeste del orógeno. Sísmicamente, la sección más occidental de la FNP es la que en la actualidad presenta una mayor actividad en los Pirineos (Souriau y Pauchet, 1998; Souriau et al., 2001; Dumont et al., 2015). El cabalgamiento frontal Norpirenaico cabalga hacia el $\mathrm{N}$ sobre la cuenca de Aquitania, que está formada por un relleno sedimentario sinorogénico que se inicia con un depósito potente de turbiditas en el Cretácico Superior (Déramond et al., 1993). Tras el depósito de carbonatos de plataforma durante el Paleoceno y principios del Eoceno se depositaron unos 4700 m de sedimentos continentales aluviales y fluviales del Eoceno (Buis y Cugni, 1978) o Eoceno- Oligoceno Inferior (Fischer, 1984). La parte más occidental de la cuenca de Aquitania contiene una gran cuenca mesozoica enterrada, la cuenca de Arzacq, que acumuló unos $3500 \mathrm{~m}$ de sedimentos marinos durante el Cretácico Inferior. Actualmente, la potencia de la serie mesozoico-cenozoica de la cuenca de Arzacq es de unos $10 \mathrm{~km}$ en su extremo meridional (Daignières et al., 1994; Teixell, 1998).

La Zona Axial comienza al $S$ de la falla Norpirenaica y aflora como una banda de rocas paleozoicas de anchura variable con dirección E-O formada por rocas metamórficas deformadas por estructu- ras variscas e intruidas por granitos y granodioritas del Carbonífero Superior, cuando todavía se estaban desarrollando las últimas estructuras variscas. La mayor parte de la Zona Axial muestra una deformación superpuesta de estructuras alpinas vergentes al sur, formando un apilamiento antiformal responsable de su exhumación (Fischer, 1984; Déramond et al., 1985; Williams, 1985; Muñoz, 1992; Vergés et al., 1995; Teixell, 1998).

La Zona Surpirenaica representa la rama meridional de los Pirineos, en la que se producen cabalgamientos alpinos dirigidos hacia el $\mathrm{S}$ de tipo thin-skinned limitados por el sur por el cabalgamiento frontal Surpirenaico. Los cabalgamientos transportan a techo una cuenca sinorogénica de varios miles de metros de potencia (cuenca Surpirenaica) formada por sedimentos de edad Eocena a Miocena de tipo turbidítico, deltaico y continental (Puigdefábregas, 1975; Teixell y García-Sansegundo, 1995). Esta cuenca de antepaís está dividida en dos subcuencas: JacaPamplona al O yTremp-Graus al E separadas por altos anticlinales formados sobre rampas oblicuas. EI cabalgamiento frontal Surpirenaico limita por el sur con el borde $\mathrm{N}$ de la cuenca del Ebro. Esta cuenca tiene su máxima potencia de hasta $5000 \mathrm{~m}$ en el $\mathrm{N}$, decreciendo hacia el $\mathrm{S}$, y recibe también los sedimentos de la cadena Ibérica y las cadenas CosteroCatalanas que la limitan por el SO y SE. La edad de los materiales abarca desde el Cretácico SuperiorPaleoceno hasta el Mioceno de los materiales que llegarían a fosilizar el sistema de cabalgamientos Surpirenaicos (IGME, 1990; Anadón y Roca, 1996; Coney et al., 1996).

\section{Estudios sísmicos previos de la corteza}

Los complejos procesos de interacción entre las placas Europea e Ibérica han marcado la arquitectura cortical de los Pirineos, dando lugar a importantes variaciones laterales del espesor cortical, tanto en su zona oriental como occidental, tal y como queda patente en los trabajos sísmicos de refracción y reflexión realizados desde finales de los 70 (Gallart et al., 1981; Daignières et al., 1981). Ambos autores evidencian un engrosamiento cortical generalizado en el sector central de la cordillera y un adelgazamiento hacia sus extremos. En la zona occidental de los Pirineos, los trabajos realizados por Gallart et al. (1981) y Daignières et al. (1981) muestran como la morfología del Moho pasa bruscamente de una potencia cortical máxima de unos $45 \mathrm{~km}$ en la Zona Axial de los Pirineos (estación PW17), adelgazándose a unos $25 \mathrm{~km}$ en el área Norpirenaica (estaciones 
PW10-09), mostrando el característico salto del Moho entre la corteza Ibérica del sur y la corteza Europea del norte.

El perfil de sísmica de reflexión profunda ECORSArzacq permitió interpretar la estructura del sector occidental de los Pirineos a niveles profundos, mostrando la placa Europea, con el Moho situado a unos 28-30 km, que indenta en la corteza Ibérica (Daignières et al., 1994; Teixell, 1998). El perfil ECORSArzacq (Teixell, 1998) muestra una profundidad del Moho a unos $27 \mathrm{~km}$ a la altura de la estación PW06.

El perfil $\mathrm{P}-1$, de dirección $\mathrm{E}-\mathrm{O}$, y el perfil $\mathrm{P}-8$, de dirección ENE-OSO, de la campaña Vasco (Pedreira et al., 2003) muestrean en parte de su trazado el área que es objeto de interés en este trabajo (Fig. 1). El perfil 1 presenta una estructura muy compleja producto de la orogenia Alpina, en la que se puede identificar el resultado de la colisión entre las placas Ibérica y Europea, mostrando una profundidad del Moho lbérico a unos $45 \mathrm{~km}$ a la altura de la estación PW21. Por otro lado, el perfil 8 presenta una estructura cortical resultado de la colisión entre las placas Ibérica y Europea acotando profundidad del Moho Europeo a unos $30 \mathrm{~km}$ de profundidad a la altura de la estación PW08 (Pedreira et al., 2003).

El perfil Pyrope occidental del presente trabajo ha sido analizado anteriormente por Chevrot et al. (2015) mediante técnicas de funciones receptoras y por Wang et al. (2016) aplicando técnicas de inversión de forma de onda para fases telesísmicas. El modelo propuesto por estos autores presenta una intrusión mantélica que alcanza los $10 \mathrm{~km}$ de profundidad en la zona central del perfil. El límite corteza-manto de la placa Ibérica lo sitúan a unos $35 \mathrm{~km}$ de profundidad en el extremo SE llegando a $50 \mathrm{~km}$ en el sector central. La morfología y las profundidades del Moho propuestas para la placa Europea concuerdan con propuestas en el perfil ECORS-Arzacq, situándolo unos $30 \mathrm{~km}$ de profundidad.

La base de datos de la morfología del Moho en la península lbérica, sus márgenes continentales y el $\mathrm{N}$ de Marruecos, obtenida mediante la recopilación de perfiles sísmicos de fuente controlada y funciones receptoras, realizada por Díaz et al. (2016) se ha utilizado para extraer secciones de la topografia del Moho del sector oriental y occidental del Pirineo, coincidentes con el área de estudio de este trabajo. Dichas secciones presentan una superficie promedio que se empleará para acotar aquellas zonas en las que no se disponga de información suficiente.

Los datos de las estaciones Pyrope de los perfiles $\mathrm{N}-\mathrm{S}$ y E-O del sector oriental de los Pirineos han sido analizado por Díaz et al. (2018) aplicando técnicas de función receptora utilizando telesismos. Las imáge- nes obtenidas de la topografía del Moho en el sector oriental del Pirineo con esta técnica muestran el Moho a unos $40 \mathrm{~km}$ de profundidad en el sector occidental del perfil E-O ascendiendo hasta aproximadamente $20 \mathrm{~km}$ de profundidad en la sección oriental a la altura de Cap de Creus. Por otro lado, el perfil N-S muestra un Moho a unos 35-40 km de profundidad adelgazándose ligeramente hacia el $\mathrm{N}$ hasta los $30 \mathrm{~km}$ (Díaz et al., 2018).

\section{Análisis e interpretación de los resultados del sector oriental de los pirineos}

Para generar los ensamblajes sísmicos y deducir los modelos de velocidad del sector oriental de los Pirineos se analizaron tres terremotos ocurridos en el año 2015. Según el catálogo del ICGC (ICGC, 2000), las magnitudes de estos sismos fueron de $3,2.5$ y 4.4 ML, localizándose en Toses, Camprodón y L'Escala, respectivamente (Tabla 1). Estos mismos sismos fueron registrados por el IGN, la red francesa RéNaSS (RESIF, 1995) y las estaciones de la red temporal PYROPE.

\section{Relocalización epicentral}

Con el fin de relocalizar de forma precisa de las fuentes sísmicas y obtener sus tiempos de origen. Se obtuvieron los tiempos de llegada de las fases $\mathrm{P}$ y $\mathrm{S}$ de todos los eventos y estaciones disponibles en un radio de $130 \mathrm{Km}$, y se llevaron a cabo una serie de pruebas empleando los programas Hypo71 y HypoEllipse.

La primera prueba consistió en invertir de las lecturas $\mathrm{P}$ y $\mathrm{S}$ de todas las estaciones de la base de datos con los programas Hypo71 y HypoEllipse. El RMS de las localizaciones resultantes fue bastante elevado, debido principalmente a los residuos (diferencia entre el tiempo observado y el calculado por el programa) de las estaciones más alejadas, ya que la heterogeneidad de esta región no está bien representada por un modelo 1D. El GAP o cobertura azimutal (ángulo máximo que existe entre dos estaciones contiguas que registran un terremoto) fue un poco mayor que el de las redes permanentes, debido a que no se utilizaron sus estaciones más lejanas. Aprovechando la posibilidad de emplear varios modelos de velocidades a la vez con el programa HypoEllipse, la siguiente prueba consistió en dividir el área en regiones y asignar un modelo de velocidad 1D distinto a cada grupo de estaciones dentro de esas regiones, 
Amanda Antonio-Vigil, et al., 2019. Estudio cortical del Pirineo mediante refracción y... Boletín Geológico y Minero, 130 (3): $417-444$

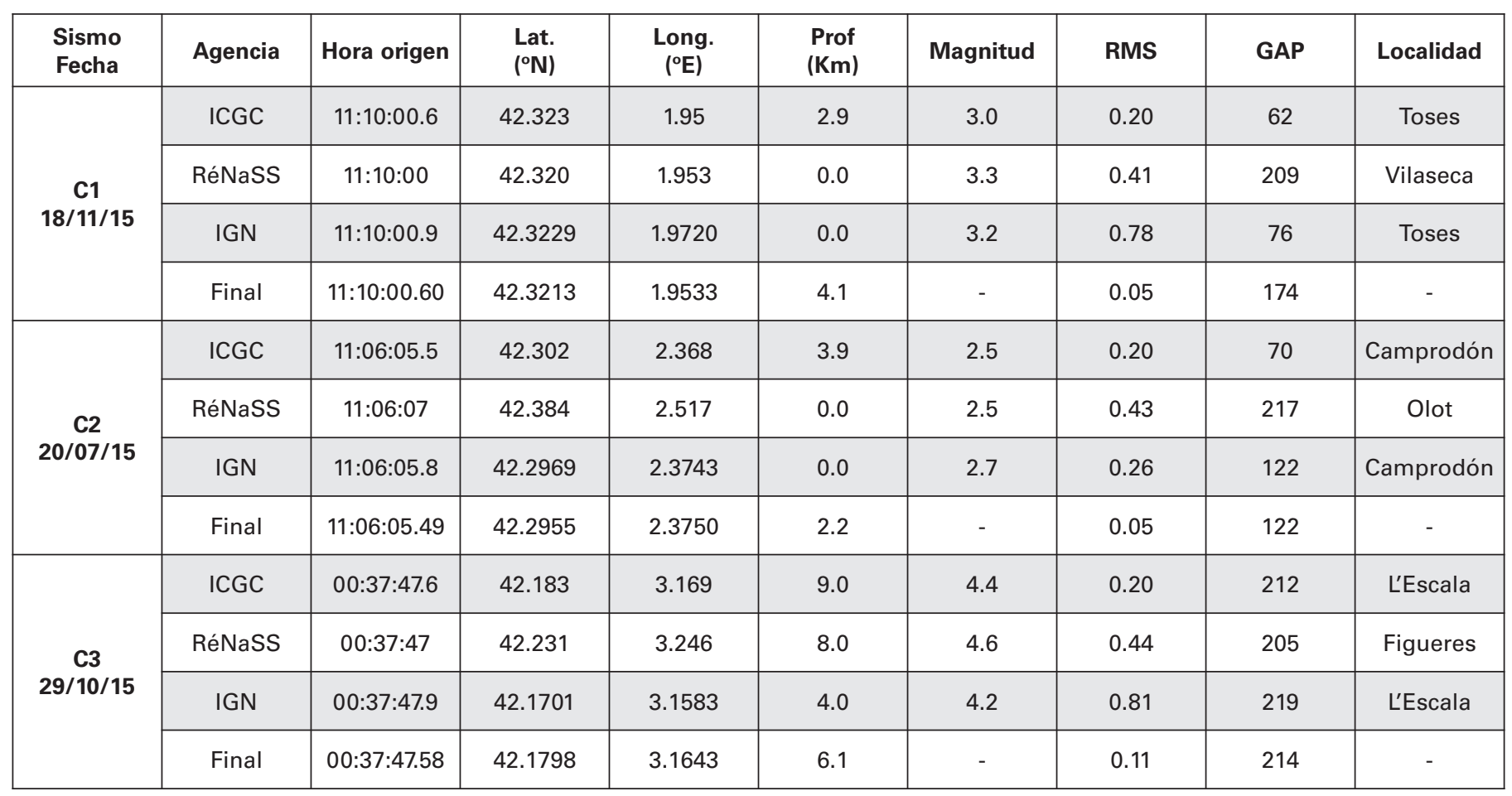

Tabla 1. Localizaciones hipocentrales de los tres terremotos analizados en esta área de estudio obtenidas por el ICGC, RéNaSS, el IGN y las finales propias de este trabajo. Se muestra la fecha y la hora de origen de los terremotos las coordenadas epicentrales, la profundidad, la magnitud, el RMS, el GAP y la localidad más cercana al epicentro. Las magnitudes se encuentran en: ML (ICGC), MLv (RéNaSS) y mbLg (IGN).

Table 1. Hypocentral locations of the three earthquakes analysed in this area obtained by the ICGC, RéNaSS, IGN and the final locations obtained in this study. The date and origin times of the earthquakes, epicentral coordinates, depth, magnitudes, RMS, GAP and the nearest village to the epicentre are shown. The magnitudes are: ML (ICGC), MLv (RéNaSS) and mbLg (IGN).

simulando un modelo pseudo 3D. El RMS final obtenido en la mayoría de los casos resultó igual de elevado que en los casos precedentes, indicando que simplificar un bloque 3D con varios modelos 1D, tampoco se ajusta bien a la compleja realidad de la zona de estudio. Finalmente, a la luz de los resultados obtenidos en las pruebas anteriores se decidió simplificar el problema invirtiendo las lecturas $\mathrm{P}$ y $\mathrm{S}$ de las estaciones más cercanas al epicentro con el programa Hypo71 mediante un modelo 1D de dos capas más sencillo y adaptado a cada región epicentral. En este caso, al estar considerando únicamente las estaciones cercanas, sólo se están registrando las fases que se propagan por las capas más superficiales de la corteza y evitando la influencia de las heterogeneidades regionales (Antonio-Vigil, 2017).

La construcción de los ensamblajes definitivos y el cálculo de distancias se realizó con los resultados de esta última aproximación (Fig. 2; Tabla 1). Las localizaciones obtenidas son más precisas que las calculadas por los distintos servicios sismológicos permanentes individualmente (IGN, ICGC y RéNaSS) al disponer de más datos cercanos alrededor del epicentro e incluir lecturas más detalladas de todas las redes permanentes y temporales disponibles, llegando a haber diferencias de entre cientos de metros a decenas de kilómetros (Antonio-Vigil, 2017).

\section{Construcción e interpretación de los ensamblajes}

El primer paso antes de poder empezar a modelizar consiste en identificar y correlacionar todas las fases sísmicas presentes en los registros, correspondientes a las ondas refractadas y reflejadas en los diferentes niveles de la corteza. Los ensamblajes sísmicos se presentan empleando una velocidad de reducción de $6 \mathrm{~km} / \mathrm{s}$. Se denominará Cataluña 1 al perfil E-O y Cataluña 2 al N-S. Durante la interpretación de los ensamblajes se identificaron refracciones en la parte superior de la corteza $(\mathrm{Pg})$ y reflexiones en la superficie corteza media-corteza inferior (PcP), así como reflexiones en la discontinuidad de Mohorovicic (PmP). 


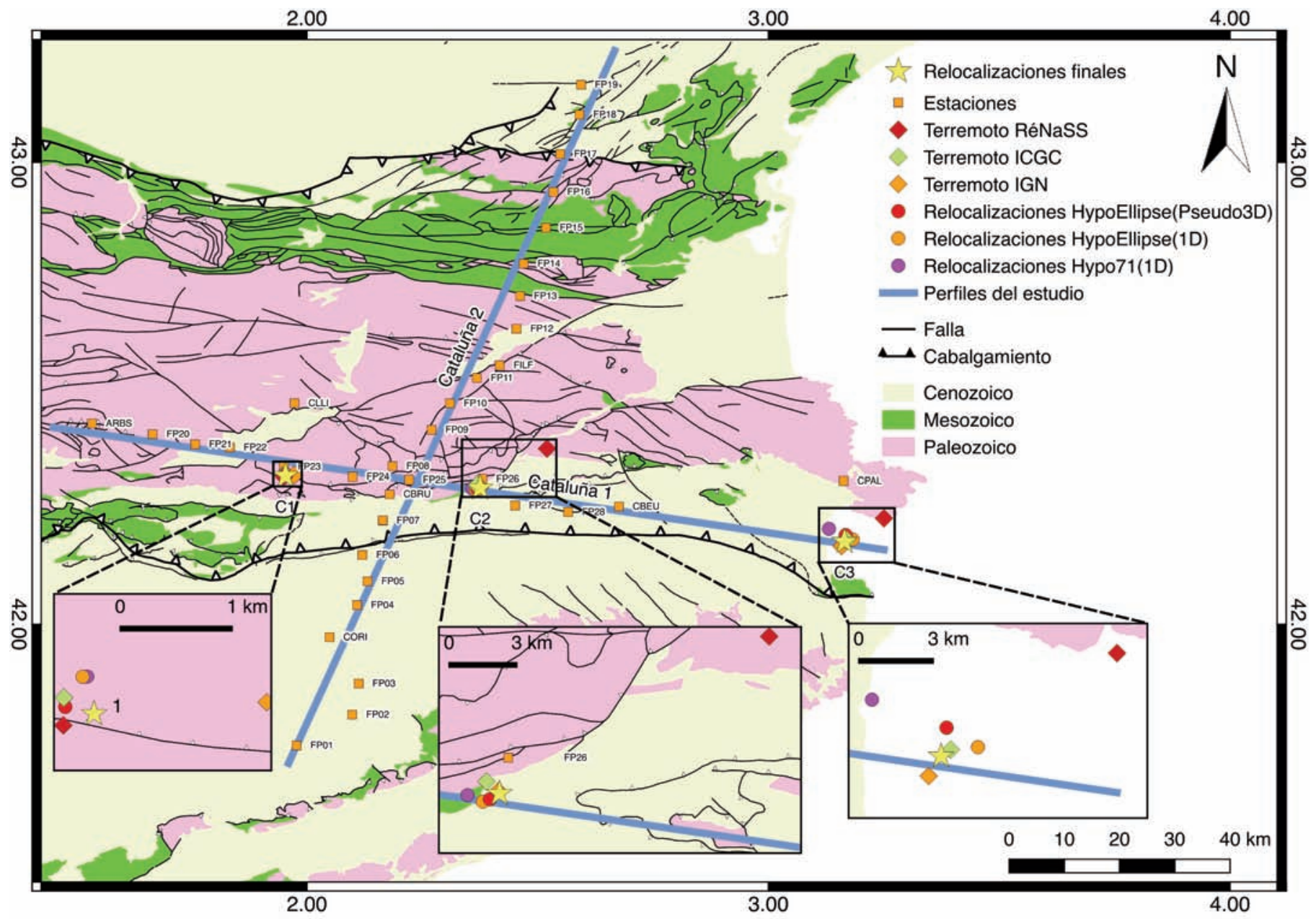

Figura 2. Mapa de situación, general y específico, de las diferentes localizaciones epicentrales de los terremotos analizados en el sector oriental de los Pirineos según las distintas redes permanentes presentes en la región y las pruebas realizadas en este trabajo. Con una estrella amarilla aparecen representadas las localizaciones finales obtenidas en este estudio que se han ha empleado en todos los cálculos posteriores. Con rombos de colores están representadas las localizaciones previas de dichos terremotos por los diferentes servicios sismológicos. Con círculos de colores aparecen representadas las distintas pruebas de relocalización realizadas en este trabajo.

Figure 2. General map and zoom showing the different epicentral locations of the earthquakes analysed in the eastern sector of the Pyrenees. Locations from the different permanent networks present in this area and the tests carried out in this work are shown. Yellow stars indicate the final locations obtained in this study, used in all later calculations. Previous locations carried out by the seismological services are represented with coloured diamonds. Coloured circles show the different relocation tests performed in this study.

En el perfil Cataluña 1, con una longitud de $152 \mathrm{~km}$ (Fig. 2), se emplearon un total de tres terremotos como fuentes sísmicas (C1, C2 y C3), situados a 44,78 y $144 \mathrm{~km}$ del origen del perfil respectivamente. Los sismos se encuentran prácticamente alineados con las estaciones de registro, con una separación perpendicular de la línea de tan sólo $3 \mathrm{~km}$ en el primer caso y $0.5 \mathrm{~km}$ en el de los dos últimos.

En el ensamblaje del terremoto $\mathrm{C}_{1}$ (Fig. 3A), las primeras llegadas se han relacionado, tanto hacia el $\mathrm{E}$ como el $\mathrm{O}$, con la llegada de las ondas directas, las refracciones en la parte más somera de la corteza superior, fase $\mathrm{Pg}$. La velocidad aparente de estas fases es de unos $6 \mathrm{~km} / \mathrm{s}$, apareciendo prácticamente horizontal en el ensamblaje. Hacia el oeste no ha sido posible correlacionar en el ensamblaje ninguna fase sísmica más, sin embargo, hacia el este se observa una segunda llegada a offsets de entre 50 y $100 \mathrm{~km}$, que durante la modelización ha sido identificada como la fase PcP o reflexión en la superficie que separa la corteza media de la inferior.

El ensamblaje del sismo $\mathrm{C} 2$ es el que menos información aporta de los tres analizados en el perfil Cataluña 1 debido a la escasa energía del sismo, 


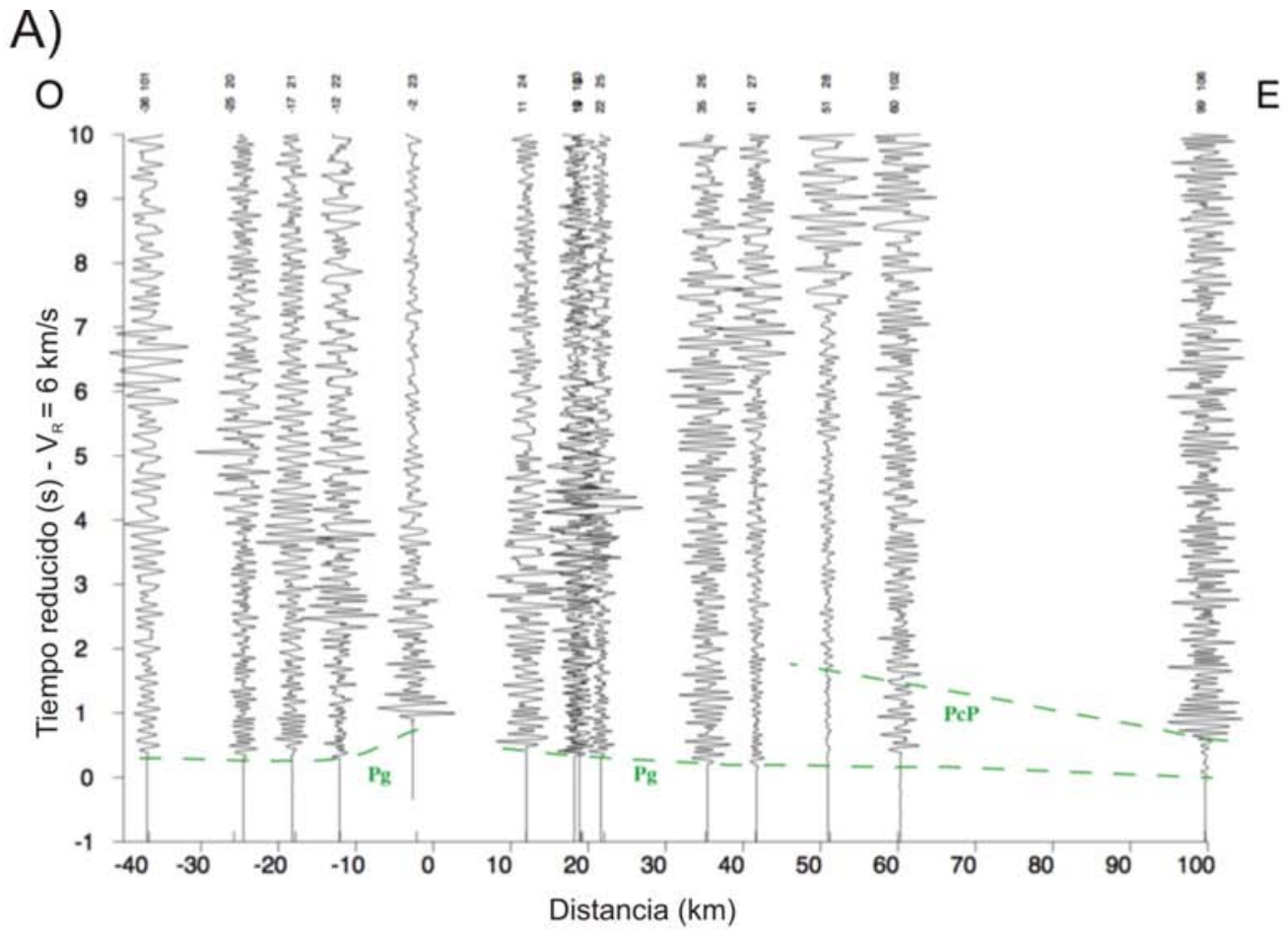

B)

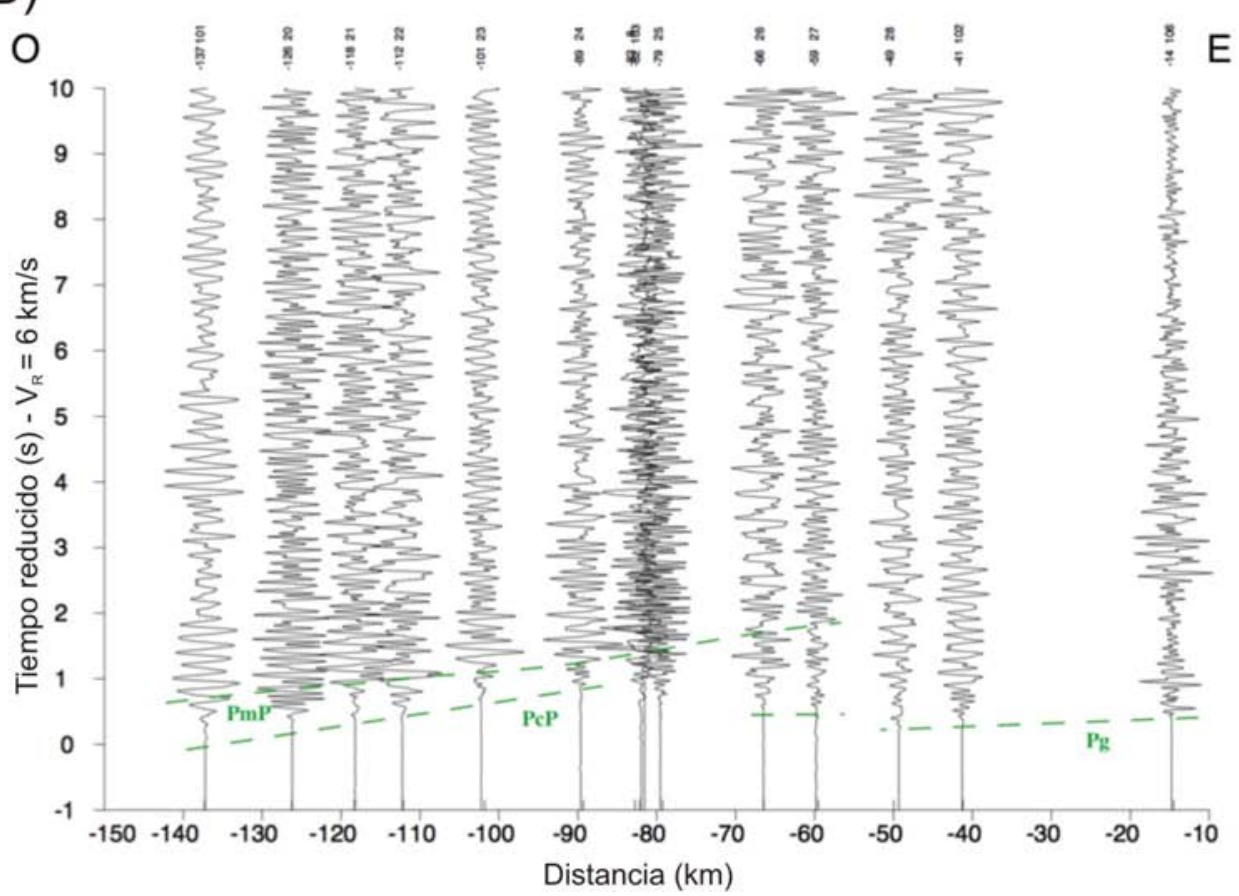

Figura 3. Ensamblajes de los terremotos del perfil Cataluña 1, en trazado verde discontinuo aparecen las diferentes fases identificadas: A) terremoto $\mathrm{C}$, las primeras llegadas corresponden a fases $\mathrm{Pg}$ y en el sector oriental se ha identificado una segunda llegada que ha sido relacionada con las fases PcP; B) terremoto $\mathrm{C} 3$, las primeras llegadas a offsets de $-70 \mathrm{a}-10 \mathrm{~km}$ se identificaron como fases Pg, en cambio, entre -90 y -140 se han relacionado con la fase PcP. A offset de entre -60 y -140 se observa una segunda llegada que ha sido relacionada con la fase PmP.

Figure 3. Seismic record sections of the earthquakes analysed in the Cataluña 1 profile. Discontinuous green lines show the different phases identified. A) $\mathrm{C} 1$ earthquake, first arrivals correspond to Pg phases, in the eastern sector a second arrival has been identified as PcP phase; B) C3 earthquakes, the first arrivals, recorded at offsets of -70 to $-10 \mathrm{~km}$, were identified as Pg phases, however, between -90 and $140 \mathrm{~km}$ they have been related to a PcP phase. At offsets between -60 and $-140 \mathrm{~km}$ a second arrival is observed and has been related to a PmP phase. 
observándose únicamente las primeras llegadas relacionadas con las refracciones en la parte más superficial de la corteza (Pg) (Antonio-Vigil, 2017).

El terremoto C3 está situado en el extremo oriental del perfil y su ensamblaje abarca offsets que llegan hasta los $140 \mathrm{~km}$. En este caso la apertura es suficientemente grande como para permitir una buena penetración y registrar fases profundas relacionadas con la base de la corteza (Fig. 3B). Las primeras llegadas pueden dividirse en dos fases. En primer lugar, a offsets de entre -10 a $-80 \mathrm{~km}$ se han identificado las llegadas de las ondas refractadas en la parte superior de la corteza $(\mathrm{Pg})$ con una velocidad aparente de unos $6 \mathrm{~km} / \mathrm{s}$. En segundo lugar, a offsets de entre -90 a -140 $\mathrm{km}$, y con una velocidad aparente superior a los 6 $\mathrm{km} / \mathrm{s}$, la fase observada se ha relacionado con las ondas reflejadas en el techo de la corteza inferior o fase PcP. Por último, en este mismo rango de offsets pero a un tiempo superior, entre 0.5 y $2 \mathrm{~s}$, se aprecia una tercera fase que ha sido relacionada con la fase PmP que corresponde a las reflexiones en el límite entre la corteza inferior y el manto.

Por lo tanto, los ensamblajes obtenidos para los terremotos $\mathrm{C} 1$ y $\mathrm{C} 3$ del perfil Cataluña 1 han permitido tener un registro de las fases relacionadas con las reflexiones profundas, fases $\mathrm{PcP}$ y $\mathrm{PmP}$, que permiten acotar el techo y el muro de la corteza inferior respectivamente, en el sector oriental del perfil. En la parte más superficial de la corteza sólo se registraron refracciones, fases $\mathrm{Pg}$, que permitieron definir, aunque fuera en promedio, la velocidad de la primera capa (corteza superior + corteza media). Para ninguno de los tres terremotos ha sido posible identificar reflexiones intracorticales que permitan definir con mayor detalle la estructura cortical, no observándose en ningún caso fases PiP que permitieran interpretar la profundidad del basamento, ni tampoco refracciones en la parte más superficial del manto (fases $\mathrm{Pn}$ ).

En el perfil Cataluña 2, de trazado N-S y una longitud de $180 \mathrm{~km}$ (Fig. 2), se emplearon como fuentes sísmicas los terremotos $\mathrm{C} 1$ y C2 localizados, respectivamente, a $69 \mathrm{~km}$ y $75 \mathrm{~km}$ del origen del perfil. Ambos terremotos se encuentran separados lateralmente 23 y $12 \mathrm{~km}$ respectivamente de la línea de estaciones de registro. La apertura total del perfil sísmico no es muy elevada lo cual repercute en una menor penetración.

El ensamblaje del terremoto $\mathrm{C} 1$ (Fig. 4A) permite identificar, tanto hacia el norte como al sur, las primeras llegadas relacionadas con las refracciones en la parte más superficial de la corteza, fase $\mathrm{Pg}$, con una velocidad aparente aproximada de $5.5-6 \mathrm{~km} / \mathrm{s}$. Hacia el norte se observa una segunda llegada que ha sido interpretada como fase PcP, es decir, una reflexión en el techo de la corteza inferior. A primera vista esta segunda llegada podría confundirse con una reflexión en la base de la corteza inferior, fase PmP, pero la modelización (integrando los datos presentes y anteriores a este estudio) permitió identificarla correctamente como fase PcP.

El ensamblaje del terremoto C2 (Fig. 4B) muestra, tanto hacia el norte como hacia el sur de la fuente, unas primeras llegadas con velocidades aparentes próximas a $5.5-6 \mathrm{~km} / \mathrm{s}$ que se han identificado como fases Pg. Hacia el sur, a offsets de $45-55 \mathrm{~km}$, y hacia el norte, a offsets de 75-90 km, se pueden observar unas segundas llegadas que, aunque muy débiles, han sido interpretadas, tras la integración de todos los datos disponibles en el modelo final, como fase PcP y no PmP.

En resumen, los datos registrados en el perfil Cataluña 2 son muy limitados, aportando principalmente información sobre las capas más superficiales de la corteza, no observándose reflexiones intracorticales que permitan acotar el basamento ni distinguir la superficie entre corteza superior y corteza media. Para la parte más superficial de la corteza sólo se han registrado fases $\mathrm{Pg}$ que permitieron establecer las velocidades promedio de la primera capa. La única reflexión registrada corresponde a la fase $\mathrm{PcP}$, que permite delimitar el límite corteza media - corteza inferior. Al encontrarse estos dos terremotos muy próximos y en el centro de la línea, están muestreando prácticamente la misma área. Además, la apertura del perfil no es lo suficientemente grande como para registrar fases relacionadas con las reflexiones en la base de la corteza, fase PmP, ni refracciones en la parte más superficial del manto, fase Pn.

\section{Modelización de gran ángulo}

La modelización de los datos del perfil Cataluña 1 proporcionados por $\mathrm{C} 1$, permiten establecer la velocidad promedio de la capa más superficial, correspondiendo al conjunto formado por la corteza superior y la corteza media, gracias al ajuste de la fase $\mathrm{Pg}$ (Figura 5A). El gradiente vertical de velocidad de esta primera capa es de $5.8-6.4 \mathrm{~km} / \mathrm{s}$, la velocidad promedio sería de unos $6.1 \mathrm{~km} / \mathrm{s}$. La segunda fase, observada a distancias de entre 90 y $150 \mathrm{~km}$, se ha identificado como las reflexiones en la base de la corteza media, fase PcP, permitiendo acotar el techo de la corteza inferior a una profundidad de $20 \mathrm{~km}$ entre los 65 y los $100 \mathrm{~km}$ del perfil.

El terremoto C2 muestra sólo una única fase en su ensamblaje, correspondiente a refracciones en la primera capa, contribuyendo al ajuste de la velocidad promedio de la capa más superficial.

El terremoto $\mathrm{C} 3$ es el que proporciona una mayor 

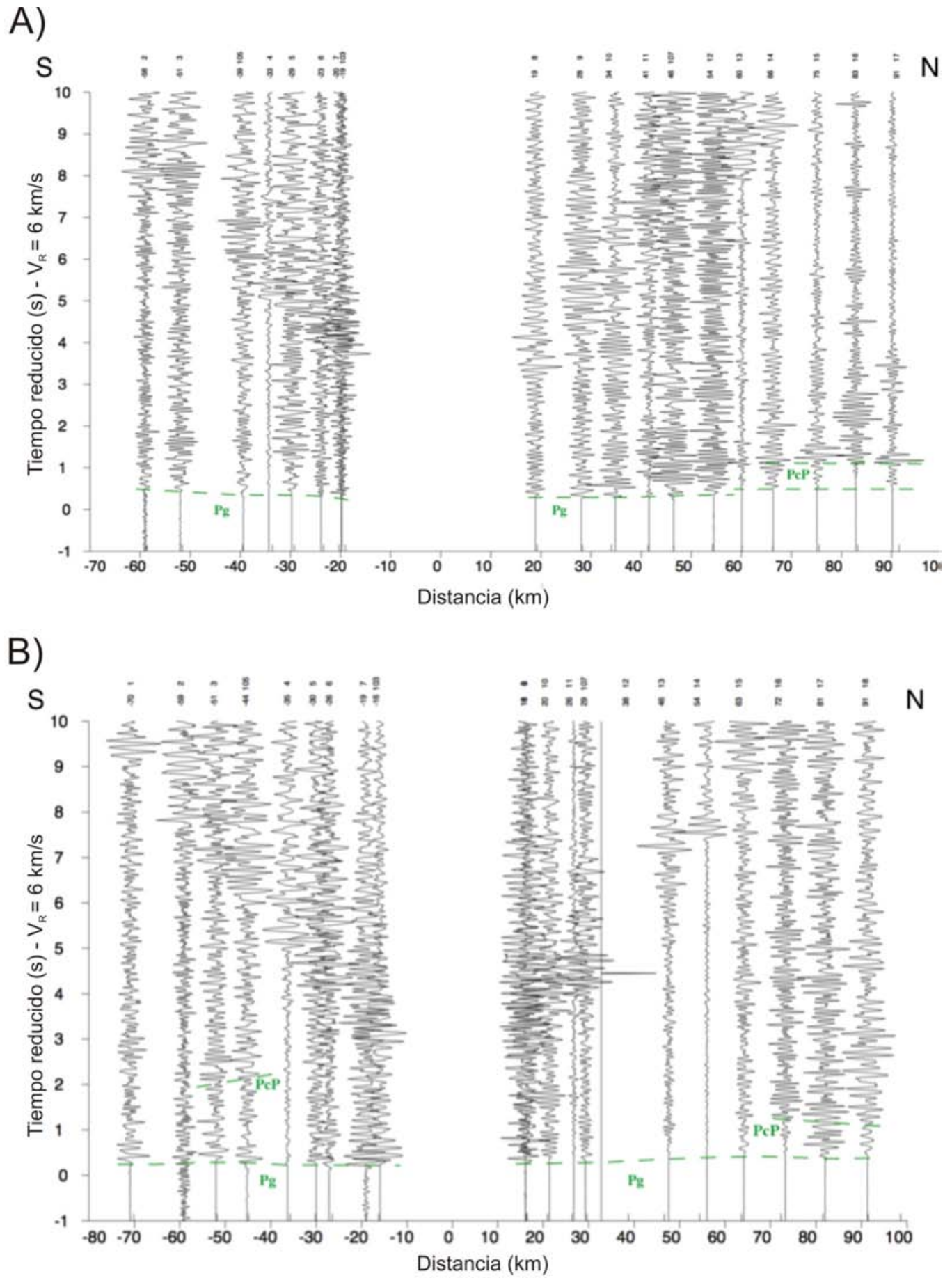

Figura 4. Ensamblajes de los terremotos del perfil Cataluña 2, en trazado verde discontinuo aparecen indicadas las distintas fases identificadas. Nótese que el espacio en blanco, sin trazas es debido a la separación de la fuente respecto a la línea de estaciones. A) terremoto $\mathrm{C} 1$ tanto hacia el sur como hacia el norte se identifica en primer lugar las refracciones en la corteza superior mientras que hacia el norte, se observa una segunda llegada que ha sido interpretada como una reflexión en el techo de la corteza inferior; B) terremoto C2 en el que se observan las mismas fases que en el ensamblaje anterior junto a una nueva fase muy tenue en el sur que ha sido interpretada también como una reflexión en el techo de la corteza inferior.

Figure 4. Seismic record sections of earthquakes analysed in the Cataluña 2 profile. Discontinuous green lines show the different phases identified. Note that the space in blank without traces is due to the separation of the source with respect to the line of stations. A) First arrivals, to the south and to the north, on earthquake $C 1$ are related to refractions in the upper crust, Pg phase. Towards the north, a second arrival is observed and has been interpreted as a reflection on the top of the lower crust, PcP phase; B) Earthquake C2 show the same phases observed in $\mathrm{C} 1$ record section, but also a weak second arrival to the south that has also been interpreted as a reflection on the top of the lower crust. 
información sobre la estructura cortical profunda del modelo Cataluña 1 (Fig. 5B). Al igual que en el caso de C1 y $\mathrm{C} 2$, se observa una primera llegada identificada como fase $\mathrm{Pg}$ que permite ajustar la velocidad promedio de la capa más superficial. La segunda fase identificada, fase PcP, aparece a distancias ente los 5 y los $65 \mathrm{~km}$, y permite acotar el techo de la corteza inferior a una profundidad de unos $18-20 \mathrm{~km}$ entre los 100 y los $125 \mathrm{~km}$ aproximadamente. A distancias de entre 5 y $85 \mathrm{~km}$ se ha identificado una tercera fase que correspondería con las reflexiones en la base de la corteza, PmP. Esta fase proporciona información de la profundidad a la que se encuentra el Moho en el sector oriental del perfil, acotándolo a una profundidad que va de los 25 a los $30 \mathrm{~km}$, entre los 125 y los $100 \mathrm{~km}$ del origen. La velocidad de la corteza inferior se ha fijado a $6.7-6.8 \mathrm{~km} / \mathrm{s}$.

La modelización de los registros del perfil Cataluña 1, permite obtener como resultado un modelo relativamente simple de dos capas, siendo la primera de ellas un promedio de la corteza superior y la corteza media, y la segunda la corteza inferior (Fig. 6). La profundidad de dichas capas sólo se ha podido acotar parcialmente en el sector más oriental del modelo indicado con una línea negra más gruesa. En aquellas zonas en las que no se disponía de datos propios suficientes para acotar la morfología de las superficies de las diferentes capas, se han modelizado siguiendo la topografía observada por otros autores. La capa más superficial muestra una potencia de unos $15 \mathrm{~km}$ en su extremo más oriental, mientras que la capa subyacente presenta una potencia de unos 10 $\mathrm{km}$ de espesor. En el extremo occidental la base de la primera capa se ha fijado a aproximadamente $30 \mathrm{~km}$ de profundidad y la segunda a unos $40 \mathrm{~km}$, generando una rampa que profundiza hacia el $\mathrm{O}$ tal y como se observa tanto en los estudios previos (Díaz et al., 2016) como en la imagen obtenida por las funciones receptoras a lo largo del mismo perfil (Díaz et al., 2018). El gradiente vertical de velocidades de la primera capa es de 5.8-6.4 km/s, mientras que en la corteza inferior se ha fijado a unos 6.7-6.8 km/s. Debido a la resolución de los datos no se puede obtener un modelo más detallado diferenciando la corteza superior y la corteza media, así como los materiales cenozoicos presentes en el extremo oriental, que deberían mostrar una disminución apreciable de la velocidad.

En el caso del modelo Cataluña 2, las fases proporcionadas por el terremoto C1 (Fig. 7A) y C2 (Fig. 7B) permiten acotar únicamente la primera capa del modelo que, igual que en el perfil anterior, correspondería al conjunto de la corteza superior y la corteza media. La velocidad en el interior de dicha capa ha sido acotada por las fases $\mathrm{Pg}$, mientras que ha sido posible delimitar algunos segmentos de su base mediante la fase PcP. El resultado es una capa bastante homogénea de una potencia de aproximadamente $20 \mathrm{~km}$ y una velocidad promedio de unos 6.1 $\mathrm{km} / \mathrm{s}$, variando entre $5.7 \mathrm{~km} / \mathrm{s}$ en la parte superior de la capa a $6.4 \mathrm{~km} / \mathrm{s}$ en la inferior. Las reflexiones en el techo de la corteza inferior observadas del terremoto C1 sólo permiten acotar una franja en la zona más septentrional del perfil entre los 95 y los $110 \mathrm{~km}$, mientras que las observadas en C2 permiten acotar esta superficie entre los $40-55 \mathrm{~km}$ y los $100-125 \mathrm{~km}$, respectivamente.

El modelo obtenido para el perfil Cataluña 2 muestra una estructura muy simplificada de una única capa, con una potencia total de unos $20 \mathrm{~km}$ que corresponden al conjunto de materiales que conforman la corteza superior y la corteza media, siendo su límite inferior el techo de la corteza inferior (Fig. 8). EI gradiente vertical de velocidades de esta capa es de unos 5.8-6.4 km/s. Se trata de una capa bastante homogénea tanto en lo referente a velocidades como a morfología. Las velocidades obtenidas pueden estar afectadas por el hecho de que los dos sismos estén fuera de la línea, y el modelo se obtuvo proyectándolos en ella. Al no disponer de fases PmP, la capa inferior se ha modelizado teniendo en cuenta las velocidades y la potencia de la corteza inferior del perfil Cataluña 1, ya que deben de ser coincidentes en su punto de corte, así como las profundidades observadas por otros autores en trabajos anteriores en esta área de estudio. Con una línea gruesa negra se han marcado, sobre el modelo final, aquellas superficies que han sido acotadas en este estudio, mientras que con una línea azul se muestran las profundidades del Moho propuestas por otros autores en las zonas de corte con este perfil.

\section{Análisis e interpretación de los resultados del sector occidental de los Pirineos}

Para generar los modelos del sector occidental de los Pirineos se analizaron un total de tres terremotos ocurridos durante el año 2013, dos en Navarra, localizados respectivamente en las localidades de Salinas de Pamplona y Etxauri (sur de Pamplona), y el tercero en la vertiente francesa de los Pirineos en la localidad de Orthez. Las respectivas magnitudes fueron según el IGN de 3.9, 3.8 y 3.5 mbLg (Tabla 2; Fig. 9).

\section{Relocalizaciones epicentrales}

En la zona occidental se llevaron a cabo ensayos de 

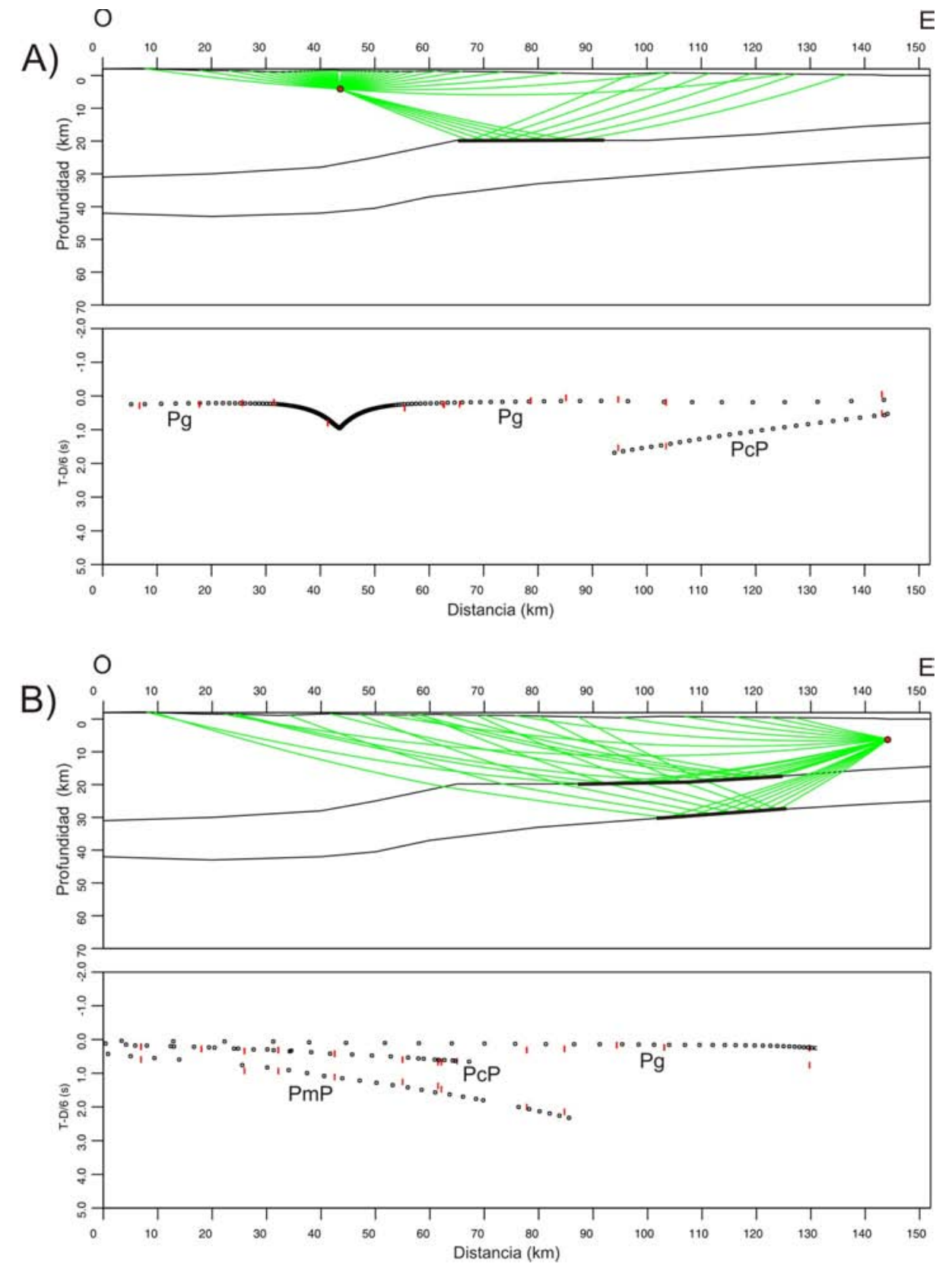

Figura 5. Resultados de las modelizaciones. En la imagen superior se muestra el trazado de rayos a través del modelo final y en la imagen inferior los ajustes de los tiempos de llegada con las fases observadas en los ensamblajes. A) Terremoto C1. B) Terremoto C3

Figure 5. Modelling results. The upper panel shows the ray tracing through the final model and the lower one the fitting of the travel times with the phases observed in the record sections. A) C1 Earthquake. B) C3 Earthquake.

relocalización similares a los realizados en la zona oriental, y como en caso anterior se optó finalmente por los resultados obtenidos con el programa Hypo71, empleando un modelo de velocidades simplificado de 2 capas, y las lecturas de las fases $P$ y $S$ de las estaciones más cercanas de cada uno de los terremotos estudiados. Las localizaciones finales incluyen las lecturas detalladas de las estaciones de todas las redes disponibles, tanto temporales como permanentes (IGN y RéNaSS) en un radio de 40-50 $\mathrm{km}$ alrededor del epicentro (Antonio-Vigil, 2017).

Las localizaciones obtenidas en este estudio muestran una diferencia en los epicentros que va de unos cientos de metros, a decenas de kilómetros en algunos casos, respecto a las localizaciones previas (Fig 9). Al eliminar las estaciones lejanas, difíciles de ajustar 


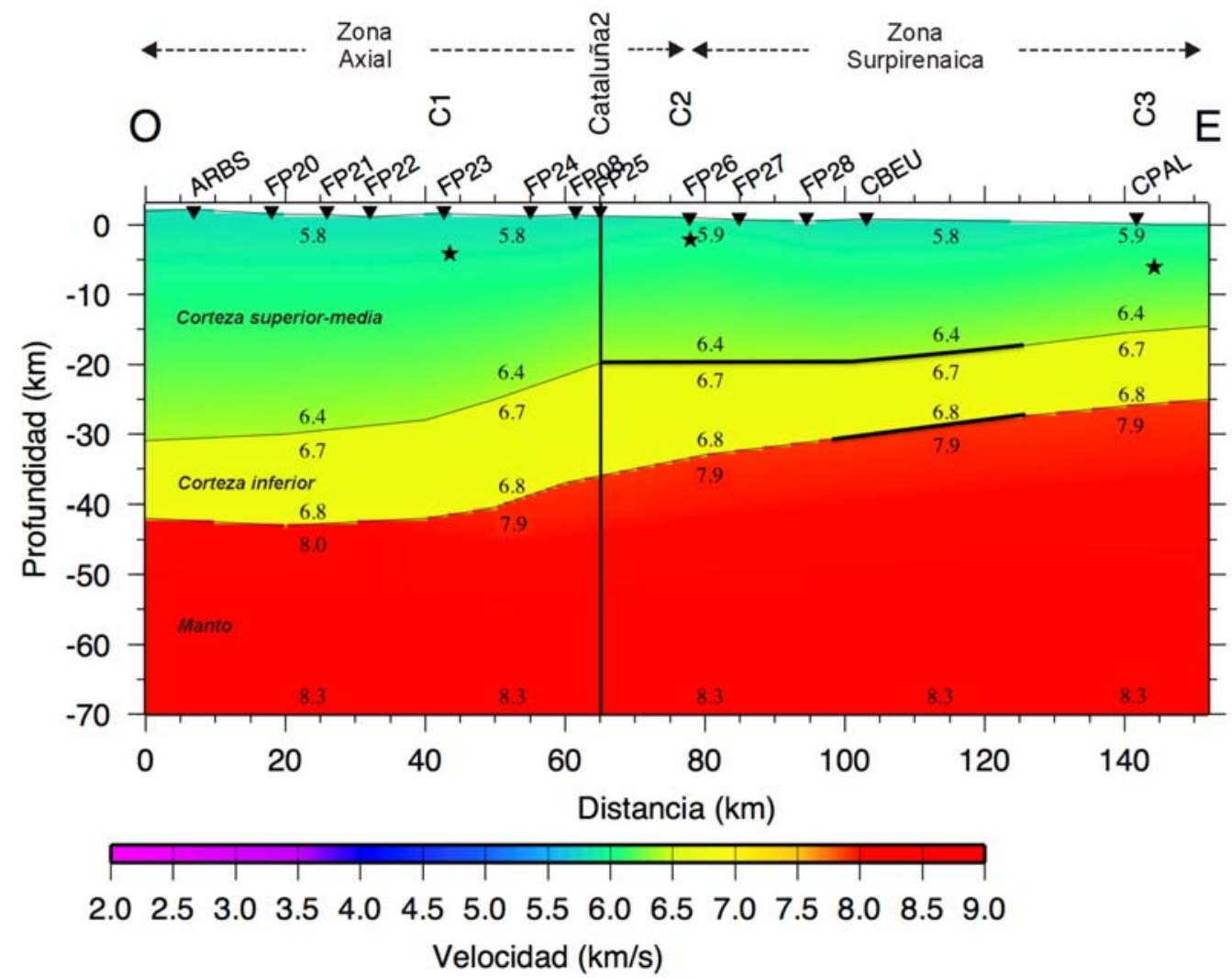

Figura 6. Modelo de velocidad-profundidad obtenido para el perfil Cataluña 1. La línea negra más gruesa resalta la parte de los límites entre niveles corticales constreñidos por los datos de este estudio. Las estrellas negras muestran la posición de los diferentes sismos. La línea vertical negra indica la zona de corte entre este perfil y Cataluña 2.

Figure 6. Velocity-depth model obtained for Cataluña 1 profile. The bold black line highlights the crustal levels constrained on this study. The black stars show the position of the different earthquakes used, and the vertical black line shows the cutting sector between this profile and Cataluña 2.

con un modelo de velocidades local que no tiene en cuenta las heterogeneidades a escala regional, el residuo RMS es menor que el de las redes permanentes, en detrimento de la cobertura azimutal o el GAP, que es mayor que el obtenido por IGN y, en general, menor que el de RéNaSS (Tabla 2). Estas localizaciones se han utilizado para la realización de todos los cálculos restantes del trabajo, como la construcción de los ensamblajes o el cálculo de las distancias.

\section{Construcción e interpretación de los ensamblajes}

El perfil Navarra, tiene una dirección NE-SO y una longitud total de $225 \mathrm{~km}$. Como fuente sísmica natural se emplearon tres terremotos N1 (Fig. 10A), N2 y N3 (Fig. 10B) situados a 40, 44 y $157 \mathrm{~km}$ del origen del perfil y, desplazados perpendicularmente con respecto a la línea de las estaciones de registro, unos 7.2, 6 y $22 \mathrm{~km}$, respectivamente. En este caso, al contrario que en Cataluña 1 y Cataluña 2, la apertura total del perfil es lo suficientemente amplia como para permitir el registro de fases profundas, ya que los sismos se encuentran en los extremos de la línea. Se debe tener en cuenta que N1 y N2 están localizados muy próximos entre sí, estando a su vez alineados al perfil, por lo que mostrarán las mismas fases con pequeñas variaciones. Sin embargo, la localización del sismo N3 está muy desplazada lateralmente al este de la línea, lo que acarreará una serie de problemas que se discutirán más adelante.

Los ensamblajes de estos terremotos han permitido detectar distintas fases, relacionadas tanto con refracciones en la parte superior de la corteza (Ps, Pg), como reflexiones en la superficie corteza superiorcorteza media (PiP), la superficie corteza media-corteza inferior tanto en la placa Ibérica $\left(\mathrm{PcP}_{\mathrm{I}}\right)$ como en la placa Europea $\left(\mathrm{PCP}_{\mathrm{E}}\right)$ y el límite corteza inferior-manto de la placa Ibérica $\left(\mathrm{PmP}_{1}\right)$ y la placa Europea $\left(\mathrm{PmP}_{\mathrm{E}}\right)$ de acuerdo con los modelos corticales aceptados para la cordillera.

Los ensamblajes de los terremotos N1 (Fig. 10A) y 
Amanda Antonio-Vigil, et al., 2019. Estudio cortical del Pirineo mediante refracción y... Boletín Geológico y Minero, 130 (3): $417-444$
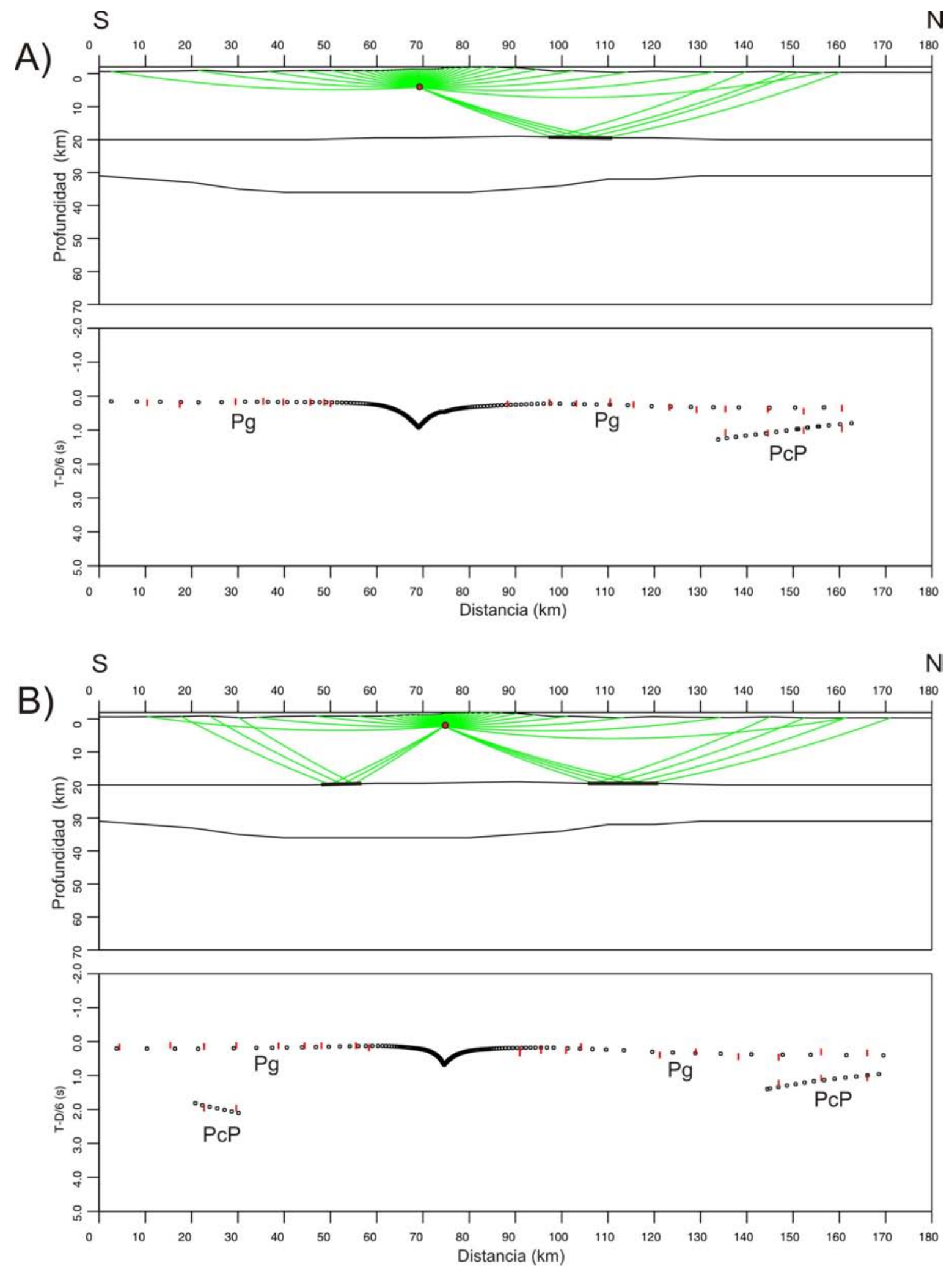

Figura 7. A) Resultados de la modelización obtenidas para el terremoto C1 apareciendo en la imagen superior el trazado de rayos a través del modelo final y en la imagen inferior los ajustes del tiempo de llegada con las fases observadas en los ensamblajes. B) Resultados para el terremoto $C 2$.

Figure 7. A) Modelling results obtained for C1 earthquake, the upper panel shows the ray tracing through the final model and the lower one the fitting of the travel times with the phases observed in the record sections. B) Results for the C2 earthquake. 


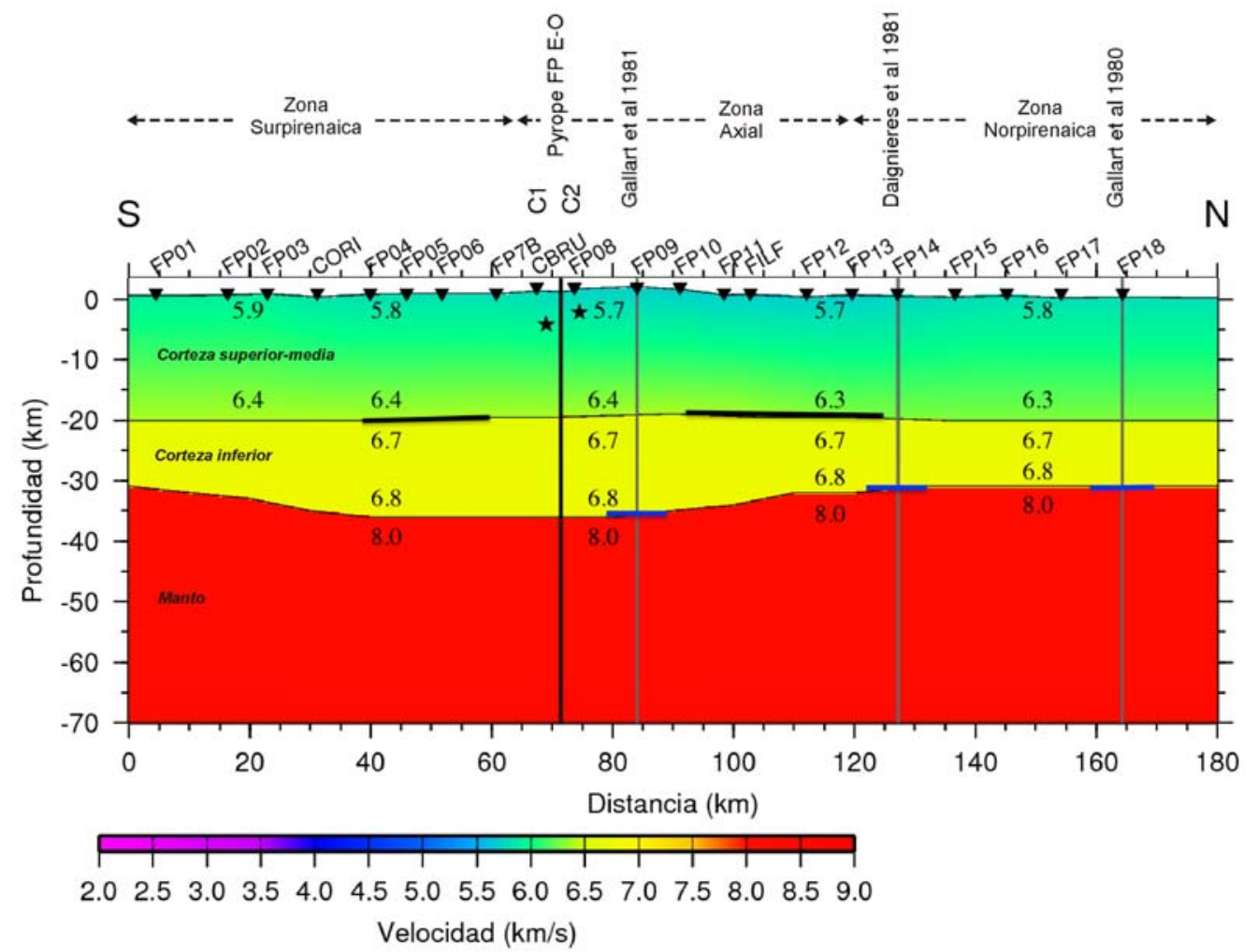

Figura 8. Modelo de velocidad-profundidad obtenido para el perfil Cataluña 2 de la zona oriental de los Pirineos. En negro aparecen resaltados los horizontes que han sido acotados por los datos de este trabajo. En azul se marcan los horizontes que han sido acotados por otros autores en esos puntos de corte. Las estrellas negras muestran la posición de los diferentes sismos. La línea vertical negra indica la zona de corte con el perfil Cataluña 1.

Figure 8. Velocity-depth model obtained for Cataluña 2 profile in the eastern Pyrenees. Black bold lines highlight the crustal levels constrained in this study. Bold blue lines mark the horizons delimited by other authors in this area. The black stars show the position of the different earthquakes analysed. The vertical black lines indicate the cutting sector between this profile, Cataluña 1 and previous profiles.

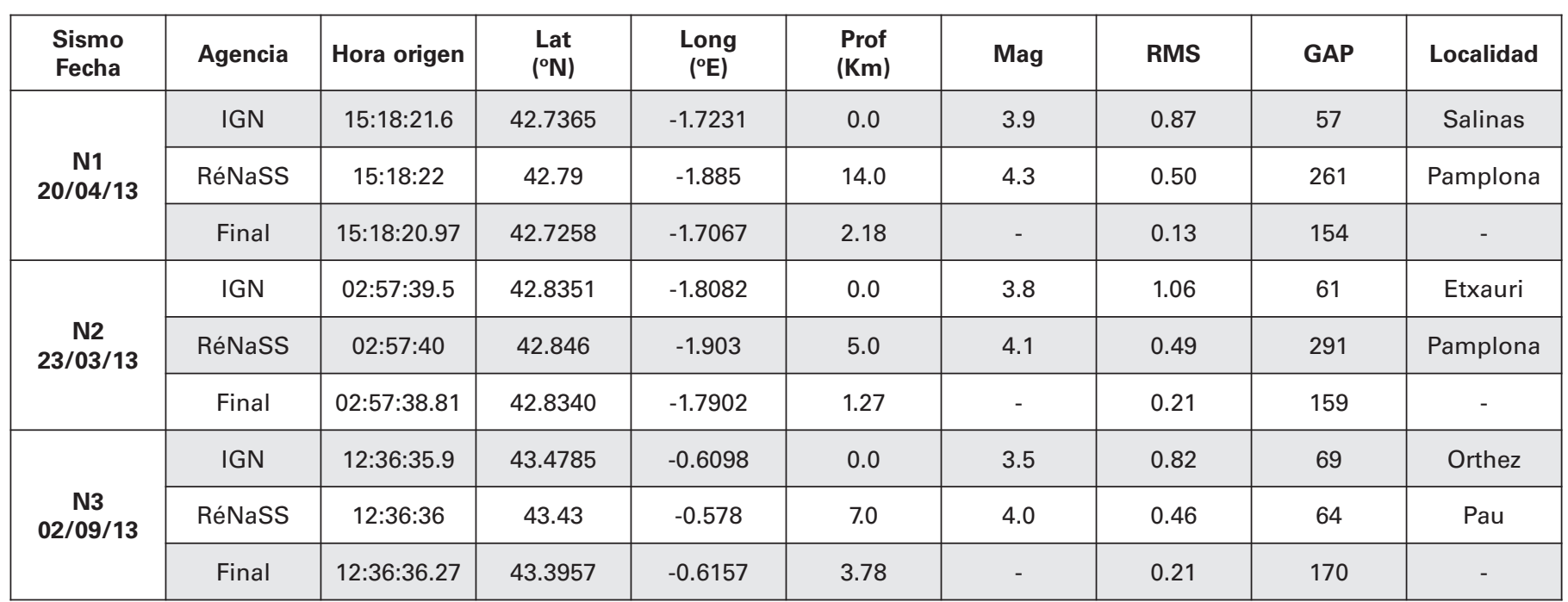

Tabla 2. Localizaciones hipocentrales de los tres terremotos analizados en esta área de estudio obtenidas el IGN, RéNaSS) y las finales propias de este trabajo. Se muestra la fecha y hora de origen, las coordenadas epicentrales, la profundidad, la magnitud, el RMS, el GAP y la localidad más cercanas al epicentro. Las magnitudes se encuentran en: mbLg (IGN) y MLv (RéNaSS).

Table 2. Hypocentral locations of the three earthquakes analysed in this area obtained by IGN, RéNaSS and the final ones obtained in this study. The date and origin times of the earthquakes, epicentral coordinates, depth, magnitudes, RMS, GAP and the nearest village to the epicentre are shown. The magnitudes are: mbLg (IGN) and MLv (RéNaSS). 


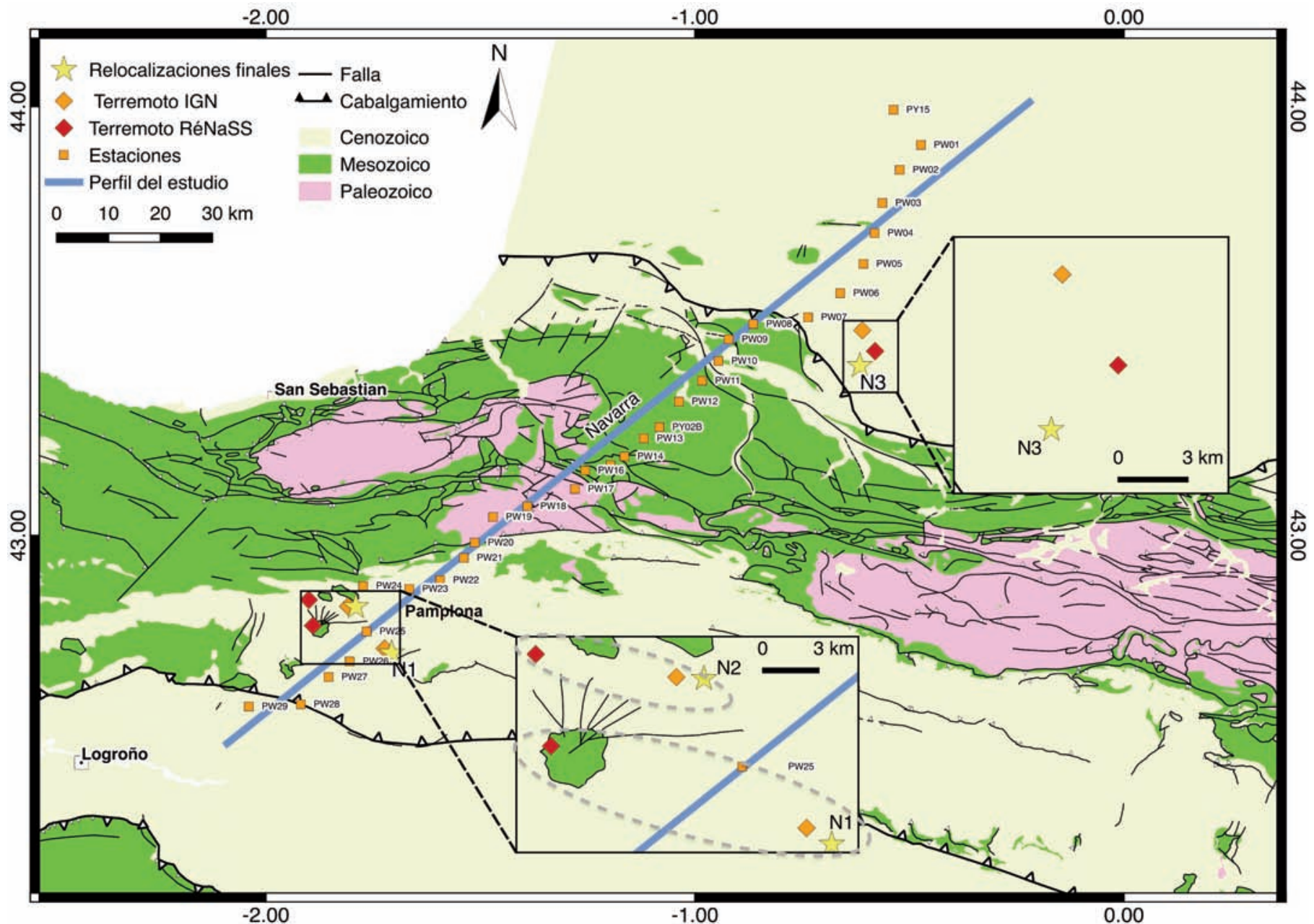

Figura 9. Mapa de situación, general y detallado, de las diferentes localizaciones de los terremotos. Con una estrella amarilla se representa la localización final del terremoto empleado en todos los cálculos restantes, mientras que con rombos de colores están representadas las localizaciones previas de dichos terremotos por los diferentes servicios sismológicos.

Figure 9. General map and zooms showing the different epicentral locations of the earthquakes analysed in the western sector of the Pyrenees. Yellow stars present the final locations obtained in this study, used in all later calculations. Previous locations carried out by seismological services are represented with coloured diamonds.

N2 permiten identificar hacia el sur dos fases. La primera llegada se ha relacionado con las refracciones en los materiales de la cuenca de Jaca-Pamplona, identificándola como fase Ps, con una velocidad aparente es de unos $5 \mathrm{~km} / \mathrm{s}$. La segunda fase ha sido relacionada con una reflexión en la superficie corteza superior-corteza media (PiP). Hacia el norte, se han identificado una mayor cantidad de fases. Las primeras llegadas se han relacionado con las refracciones en los niveles superiores, identificándola como fase $\mathrm{Ps}$, con una velocidad aparente de unos $5 \mathrm{~km} / \mathrm{s}$ hasta offsets de $40 \mathrm{~km}$. A offsets mayores hasta $110 \mathrm{~km}$, las primeras llegadas se han identificado como dos fases que se solapan, correspondiendo entre $50-90 \mathrm{~km}$ a las refracciones en la parte superior de la corteza $(\mathrm{Pg})$, con una velocidad aparente más rápida, de unos 5.5 $6 \mathrm{~km} / \mathrm{s}$, y entre $90-110 \mathrm{~km}$ a las reflexiones en el límite corteza superior - corteza media (PiP). Por otro lado, a tiempos aún mayores, se han identificado en el ensamblaje otra serie de fases que han sido relacionadas con reflexiones en niveles sucesivamente más profundos de la corteza. A offsets de entre $30 \mathrm{y}$ $110 \mathrm{~km}$ se observan dos fases diferentes. La primera de ellas, que aparece a unos 2 segundos, se atribuyó en un principio a una reflexión en la parte superior de la corteza media, sin embargo, durante la modelización fue relacionada con las reflexiones en el límite corteza media - corteza inferior de la placa Europea $\left(\mathrm{Pc}_{\mathrm{E}}\right)$. La segunda, a unos 2.5 segundos, se interpreta como las reflexiones en el límite corteza inferior - 

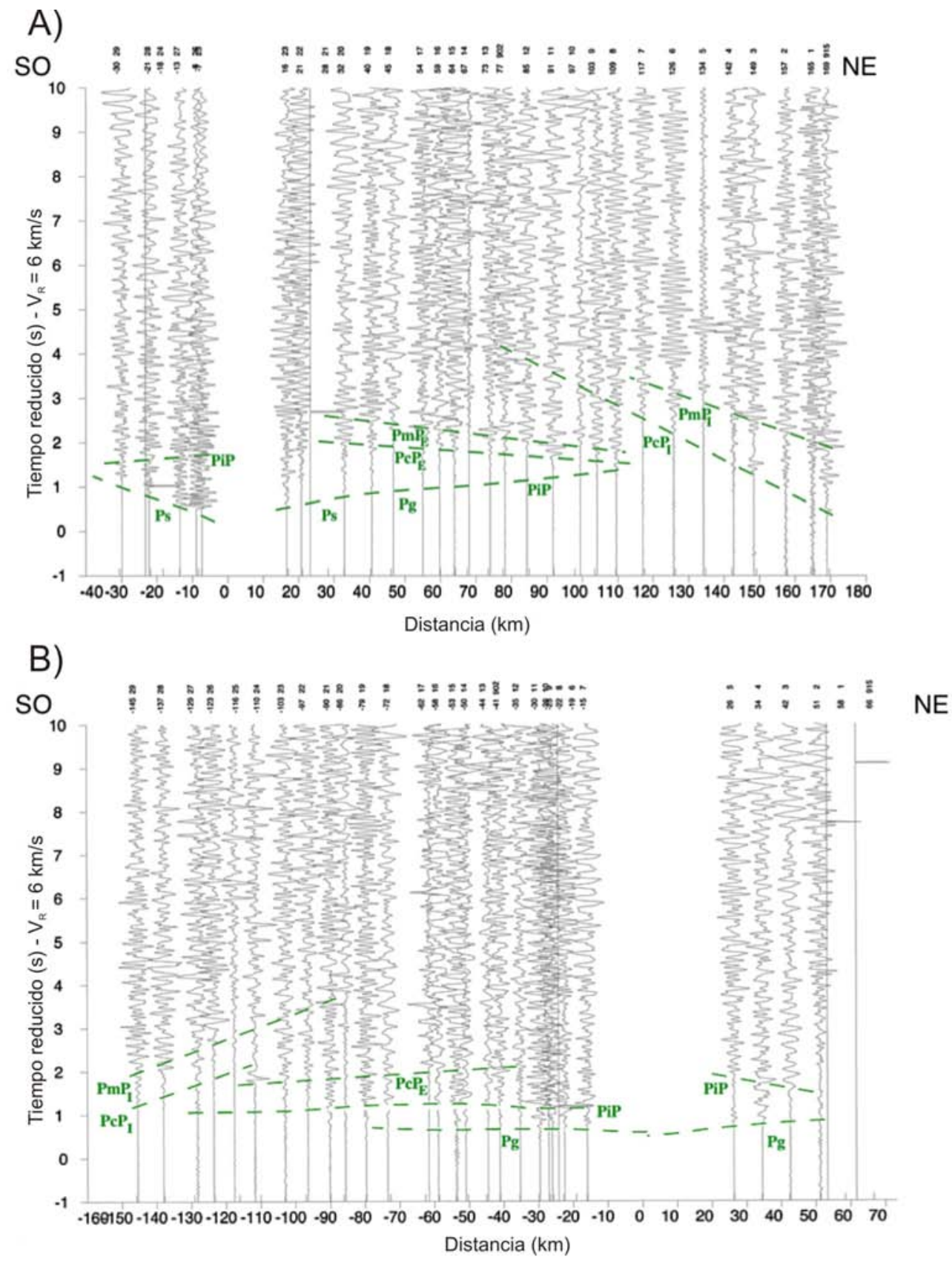

Figura 10. Ensamblajes de los terremotos del perfil de Navarra mostrando en trazado verde discontinuo las diferentes fases interpretadas: A) terremoto N1, las primeras llegadas, hasta offsets de $110 \mathrm{~km}$, se corresponden con las fases Ps, Pg y PiP. En la zona central del ensamblaje aparecen unas segundas llegadas que corresponden con las fases PcP y PmP, Europeas, mientras que en el extremo septentrional del ensamblaje la primera y segunda fase se ha asociado a la PcP y PmP Ibérica, respectivamente. B) terremoto N3, las primeras llegadas, a offsets de 50 a $-80 \mathrm{~km}$, corresponden a las fases Pg. La fase PiP aparece con una segunda llegada a offsets de 5 hasta $-130 \mathrm{~km}$. En la zona central del ensamblaje, a offsets de -30 a -120 , aparece una fase muy tenue que ha sido identificada como PcP Europea. En la zona meridional del ensamblaje aparecen dos fases relacionadas con las reflexiones en el límite corteza media-corteza inferior y corteza inferior-manto de la placa lbérica.

Figure 10. Seismic record sections of the earthquakes analysed in the Navarra profile showing the different phases identified with a discontinuous green line. A) N1 earthquake, first arrivals, up to offsets of $110 \mathrm{~km}$, correspond to Ps, Pg and PiP phases. In the central sector of the record section appear a second and third arrivals that correspond to the European PcP and PmP phases. In the northern edge of the record section, the first and second arrivals have been associated to the Iberian PcP and PmP phases, respectively. B) N3 earthquake, the first arrivals, at offsets between 50 to $-80 \mathrm{~km}$, correspond to the Pg phases. The PiP phase appears as a second arrival at offsets between 5 to $-130 \mathrm{~km}$. In the central sector of the record section, at offsets between -30 to -120 , a weak phase appears that has been identified as European PCP. In the southern edge of the record section two phases related to reflections in the middle-lower crust boundary and Moho of the Iberian plate have been respectively identified. 
manto en la placa Europea $\left(\mathrm{PmP}_{\mathrm{E}}\right)$. Por último, mucho más hacia el norte, se encuentran otras dos fases. En origen se pensó que la primera de ellas, localizada entre los 0.5 - 4 segundos, debido a su elevada velocidad aparente, podría corresponder a una refracción en el manto $(\mathrm{Pn})$. Sin embargo, como se explicará más adelante, durante la modelización fue identificada finalmente como una reflexión en el límite superior de la corteza inferior de la placa Ibérica $\left(\mathrm{PcP}_{\mathrm{I}}\right)$. En cuanto a la segunda, situada a unos 2 - 3.5 segundos y con una velocidad aparente también muy elevada, fue relacionada con una reflexión en el límite corteza inferior - manto de la placa lbérica, $\left(\mathrm{PmP}_{\mathrm{I}}\right)$.

El ensamblaje del terremoto N3 (Fig. 10B) corresponde al de la fuente localizada en el extremo más septentrional del perfil de Navarra y con una mayor separación lateral respecto de la línea de estaciones. La primera fase identificada corresponde a las refracciones en la parte superior de la corteza $(\mathrm{Pg})$ y aparece de sur a norte a ambos lados de la fuente, entre los -70 y los $50 \mathrm{~km}$ respectivamente, con una velocidad aparente de unos $6 \mathrm{~km} / \mathrm{s}$ aproximadamente. Hacia el norte del ensamblaje sólo ha sido identificada una fase más, correspondiente a las reflexiones en el límite inferior de la corteza superior (PiP). Esta fase ha sido identificada también en la zona sur a offsets de entre -130 y $-15 \mathrm{~km}$, y tiempo reducido de aproximadamente 1 segundo. En el sector sur del ensamblaje, aparecen otras tres fases más, procedentes de las reflexiones en diferentes niveles de la corteza. A offsets de entre -110 y $-40 \mathrm{~km}$, y tiempo reducido de 1.52 segundos, aparece una fase que ha sido relacionada con las reflexiones en la superficie corteza media corteza inferior de la placa Europea $\left(\mathrm{PCP}_{\mathrm{E}}\right)$. En este caso, a diferencia de los ensamblajes anteriores, no se observan fases $\mathrm{PmP}_{E}$, que permitan acotar la base de la corteza Europea. Entre 1 y 2 segundos y -145 a $115 \mathrm{~km}$ aparece una fase que, al igual que en los dos casos anteriores, se pensó que podía tratarse de una refracción en el manto debido a su alta velocidad aparente $(\mathrm{Pn})$, sin embargo, fue finalmente identificada durante la modelización como una reflexión en el límite corteza media - corteza inferior de la placa Ibérica $\left(\mathrm{PcP}_{1}\right)$. Por último, a offsets de entre -145 y -90 $\mathrm{km}$ y unos 2 y 3.5 segundos de tiempo reducido, aparece una fase que ha sido relacionada con las reflexiones en el límite corteza inferior - manto de la placa Ibérica $\left(\mathrm{PmP}_{\mathrm{I}}\right)$.

\section{Modelización de gran ángulo}

El perfil Navarra atraviesa de forma ligeramente oblicua la Zona Surpirenaica, incluyendo la cuenca de
Jaca-Pamplona, la Zona Axial Pirenaica y la Zona Norpirenaica hasta la cuenca de Aquitania, estando la zona más meridional del perfil situada sobre la falla de Pamplona.

Los datos registrados para los terremotos N1 y N2 proporcionan una gran cantidad de información para el ajuste del modelo, aunque debido a su gran proximidad pueden llegar a ser redundantes. Durante la modelización se dio más peso a los datos de N1, ya que al tener mayor magnitud los registros parecen más claros. Por ello, se hará una explicación conjunta de la modelización de ambos eventos. Aquellas zonas donde los datos no han permitido modelizar la estructura, las interfases se han definido en base a los datos de experimentos precedentes.

Las fases Ps registradas en N1 y N2, permiten acotar la velocidad promedio, de alrededor $5 \mathrm{~km} / \mathrm{s}$, de una primera capa de unos $5 \mathrm{~km}$ de espesor que se acuña lateralmente hacia el $\mathrm{NE}$, interpretada como los materiales de la cuenca de Jaca-Pamplona. A offsets mayores, las fases $\mathrm{Pg}$ permiten ajustar una velocidad promedio, de 5.6-5.8 $\mathrm{km} / \mathrm{s}$, para la corteza superior. La base de la segunda capa, correspondiente a la base de la corteza superior, ha sido definida por los ajustes de la fase PiP y permitiendo definir una superficie casi plana, entre los 25 y los $80 \mathrm{~km}$ del modelo, a una profundidad aproximada de unos $10 \mathrm{~km}$. La fase $\mathrm{PCP}_{\mathrm{E}}$ permite delimitar la base de la corteza media de la placa Europea, entre los $25-35$ km y los $52-100 \mathrm{~km}$, a una profundidad de unos $20 \mathrm{~km}$. Por último, la base de la corteza inferior de la placa Europea está delimitada entre los 55 y los $100 \mathrm{~km}$ a una profundidad que va de los $20 \mathrm{~km}$ en su extremo sur a los $30 \mathrm{~km}$ en su extremo norte, mostrando una geometría ligeramente en rampa. La geometría de esta capa viene acotada por la fase $\mathrm{PmP}_{\mathrm{E}}$ registrada en el terremoto N1 (Fig. 11A).

La placa Ibérica aparece acotada por la identificación de dos fases que permiten definir las bases de las cortezas media e inferior Ibérica. La primera de ellas, la fase $\mathrm{PcP}_{1}$, permiten delimitar esa capa a una profundidad de unos $35-40 \mathrm{~km}$ entre los 70 y los 85 $\mathrm{km}$ con una ligera pendiente hacia el NE. La segunda, la fase $\mathrm{PmP}_{\mathrm{l}}$, permiten acotar el límite corteza inferior - manto entre los 80 y los $110 \mathrm{~km}$ a una profundidad de unos $42 \mathrm{~km}$ en su extremo sur llegando a alcanzar unos $52 \mathrm{~km}$ en su zona más septentrional (Fig.11A).

El terremoto N3 proporciona información desde el extremo opuesto del modelo (Fig. 11B). Sin embargo, al encontrarse este evento $22 \mathrm{~km}$ fuera de la línea, estará muestreando las estructuras pirenaicas con una orientación oblicua. Este hecho impone una cierta limitación en la modelización, ya que tanto el método como el programa utilizados asumen que las fuen- 
tes y los receptores están perfectamente alineados y que el modelo geológico es cilíndrico y lateralmente homogéneo. En este caso, al modelizar se proyectó la posición de N3 sobre la línea, sin aplicar ninguna corrección sobre los tiempos de llegada de las fases, pues para aplicar dichas correcciones sería necesario conocer a priori el modelo de velocidades objeto de estudio. Debido a la intrincada estructura geológica del orógeno, que presenta importantes variaciones laterales en su estructura, el terremoto N3 estará muestreando las estructuras de la cordillera con una orientación y ángulo ligeramente distintos a los asumidos en el modelo, dando lugar a algunas incongruencias que se discutirán a continuación.

Los datos registrados por el terremoto N3 para las capas más superficiales, permiten obtener cierta estructura en la corteza superior. Las fases $\mathrm{Pg}$ y PiP permiten acotar una zona con velocidades de 5.6-5.8 $\mathrm{km} / \mathrm{s}$, que correspondería a los materiales más consolidados del Mesozoico y Paleozoico, que llega a alcanzar una profundidad de unos $10 \mathrm{~km}$ y aflora en superficie en la zona central. La fase PiP permite definir la superficie corteza superior - corteza media entre los 100 y los $180 \mathrm{~km}$. A partir de los datos geológicos superficiales, se ha incluido en el extremo más septentrional del perfil una zona de velocidad más baja, de unos $5 \mathrm{~km}$ de potencia, acuñándose lateralmente hacia el SO y velocidades promedio de $5 \mathrm{~km} / \mathrm{s}$ relacionándola con la cuenca de Aquitania. La fase $\mathrm{PCP}_{\mathrm{E}}$ permite acotar la base de corteza media de la placa Europea, entre los 100 y los $140 \mathrm{~km}$, a una profundidad de unos $20 \mathrm{~km}$, confiriendo a la capa una geometría bastante tabular (Fig. 11B).

Los intentos de ajustar las fases $\mathrm{PcP}_{1}$ y $\mathrm{PmP}_{\mathrm{l}}$, reflejadas en el techo y la base de la corteza inferior Ibérica, respectivamente, identificadas en el ensamblaje del terremoto N3, deriva en un modelo que no es coherente con los modelos previos de la zona, ni compatible con el modelo obtenido de los terremotos N1 y N2. La posición oblicua del terremoto N3 da una visión errónea de geometría de las zonas más profundas de la corteza lbérica buzando hacia el norte, por lo que no se tuvieron en cuenta esos datos de la zona profunda tan sólo los del área más superficial.

En conclusión, en el perfil Navarra (Fig. 12) se puede apreciar una primera capa, correspondiente a los niveles superficiales y con velocidades más bajas formados por los materiales cenozoicos de la corteza superior, subdividida en dos sectores, norte y sur, que conformarían las cuencas de Aquitania y de JacaPamplona respectivamente. El sector sur tiene un gradiente de velocidades de entre $4.9-5.2 \mathrm{~km} / \mathrm{s}$ y el sector norte presenta unos rangos de velocidades de entre 4.9-5.1 $\mathrm{km} / \mathrm{s}$, siendo la potencia máxima de estas capas inferior a los $6 \mathrm{~km}$. Los niveles más consolidados de la corteza superior, formados por materiales mesozoicos y paleozoicos, han sido modelizados con una capa de geometría variable a lo largo de la línea, teniendo una menor potencia en los extremos del perfil, unos $6 \mathrm{~km}$ debajo de las cuencas cenozoicas, llegando a alcanzar los $12 \mathrm{~km}$ en el centro del perfil donde estos materiales afloran. Esta capa presenta un gradiente de velocidad de unos $5.6-5.8 \mathrm{~km} / \mathrm{s}$. La base de la corteza superior es ligeramente irregular y subhorizontal.

La corteza media se ha modelizado como dos capas de geometría y distribución de velocidades variables, apareciendo un gradiente de velocidad de unos $6.2-6.3 \mathrm{~km} / \mathrm{s}$ en el extremo sur de la línea y de unos $6.0-6.1 \mathrm{~km} / \mathrm{s}$ en el centro y extremo norte. Las fases $\mathrm{PCP}_{\mathrm{E}}$ y $\mathrm{PCP}_{1}$ detectadas permiten delimitar una corteza media de unos $8 \mathrm{~km}$ de potencia, pudiendo diferenciarse entre la corteza media de la placa Europea y la de la placa Ibérica. La Europea es aproximadamente subhorizontal, mientras que la Ibérica está inclinada hacia el norte subduciendo bajo la Europea generando una rampa.

La corteza inferior también se ha modelizado en dos capas distintas correspondientes a la placa Europea y a la placa lbérica. Las fases $\mathrm{PmP}_{1}$ y $\mathrm{PmP}_{\mathrm{E}}$ detectadas permiten delimitar parcialmente la morfología de la base de ambas capas en la zona de indentación cortical. La corteza inferior lbérica presenta una geometría y distribución de velocidades variable a lo largo de la capa, a medida que va profundizando al subducir bajo la placa Europea, llegando hasta los 45$50 \mathrm{~km}$ de profundidad en la parte central del modelo, con velocidades de 7.0-7.2 km/s. La corteza inferior Europea en cambio presenta una geometría y un gradiente de velocidad bastante constante mostrando, en la parte central del modelo, unos $10 \mathrm{~km}$ de potencia y un gradiente de velocidades de unos 6.6-6.7 $\mathrm{km} / \mathrm{s}$. La subducción y profundización hacia el norte de la corteza media e inferior lbérica se debe a la indentación hacia el sur de las corteza Europea formando una duplicación de cortezas y una raíz cortical. Algunos autores han puesto en evidencia que esta estructura cortical se prolonga tanto hacia el este en el resto del orógeno pirenaico, como hacia el oeste bajo la cuenca Vasco-Cantábrica y la cordillera Cantábrica, entre otros: Muñoz (1992), Pulgar et al. (1996), Teixell (1998), Pedreira et al. (2007, 2015), Díaz y Gallart (2009), Gallastegui et al. (2016).

En el sector norte del modelo los terremotos empleados no aportan información y se ha fijado la profundidad del Moho de la placa Europea, prácticamente constante a unos $30 \mathrm{~km}$, a partir de los trabajos previos regionales. La potencia es consistente con 

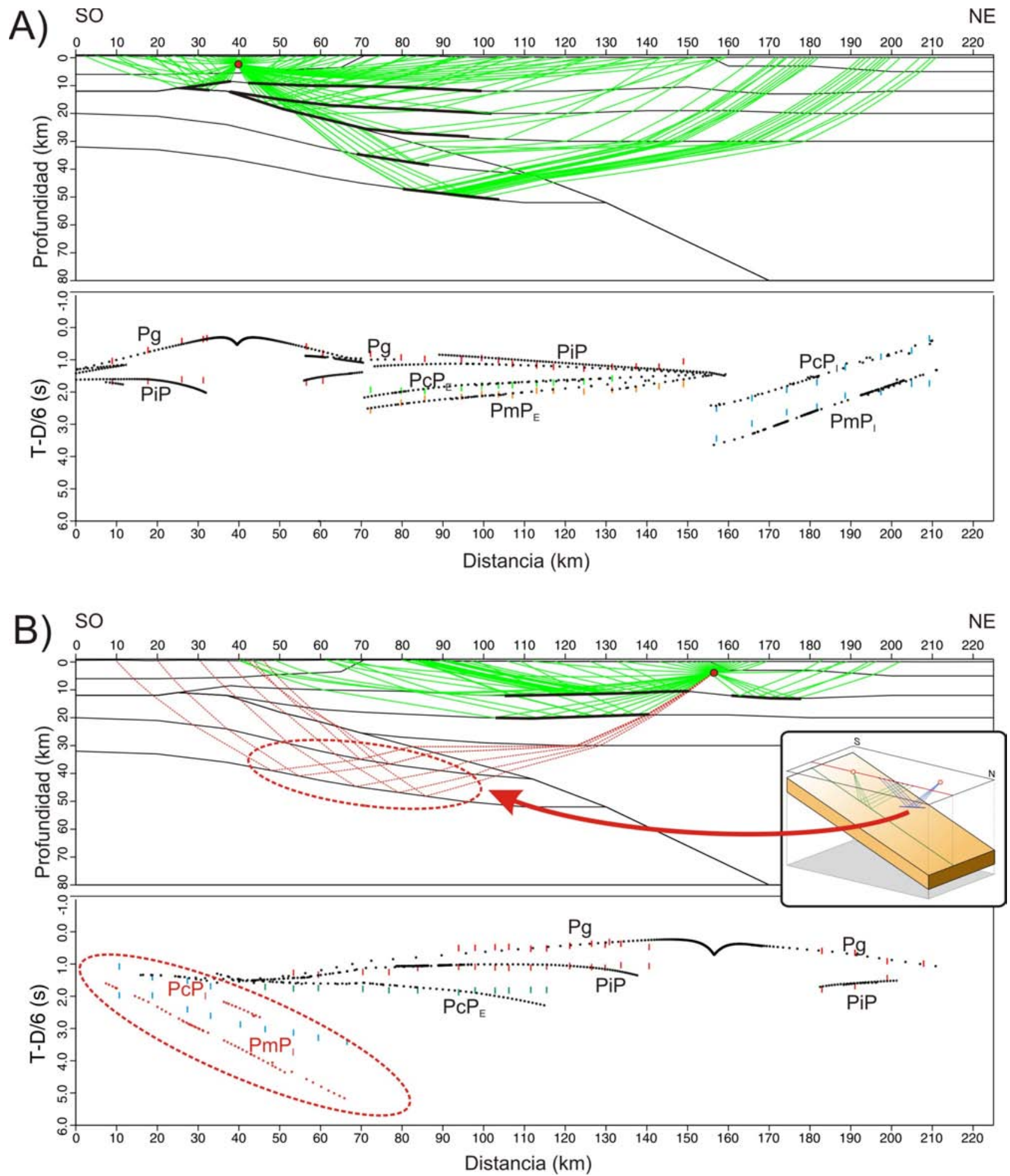

Figura 11. A) Resultados obtenidos en el perfil Navarra para el terremoto N1, en la parte superior: trazado de rayos a través del modelo final; en la parte inferior: ajustes de los tiempos de llegada con las fases observadas en los ensamblajes. B). Resultados obtenidos en el perfil Navarra para el terremoto N3. Debido a la posición oblicua de este sismo no es posible ajustar las fases de la corteza Ibérica con la geometría acotada en N1 y N2.

Figure 11. A) Modelling results obtained in the Navarra profile for the N1 earthquake. Upper panel: ray tracing through the final model. Lower panel: fitting of the travel times with phases observed in the record sections. B). Results obtained in the Navarra profile for the N3 earthquake. Due to the oblique position of this earthquake it is not possible to fit the seismic phases of the lberian crust with the geometry delimited by $\mathrm{N} 1$ and $\mathrm{N} 2$. 


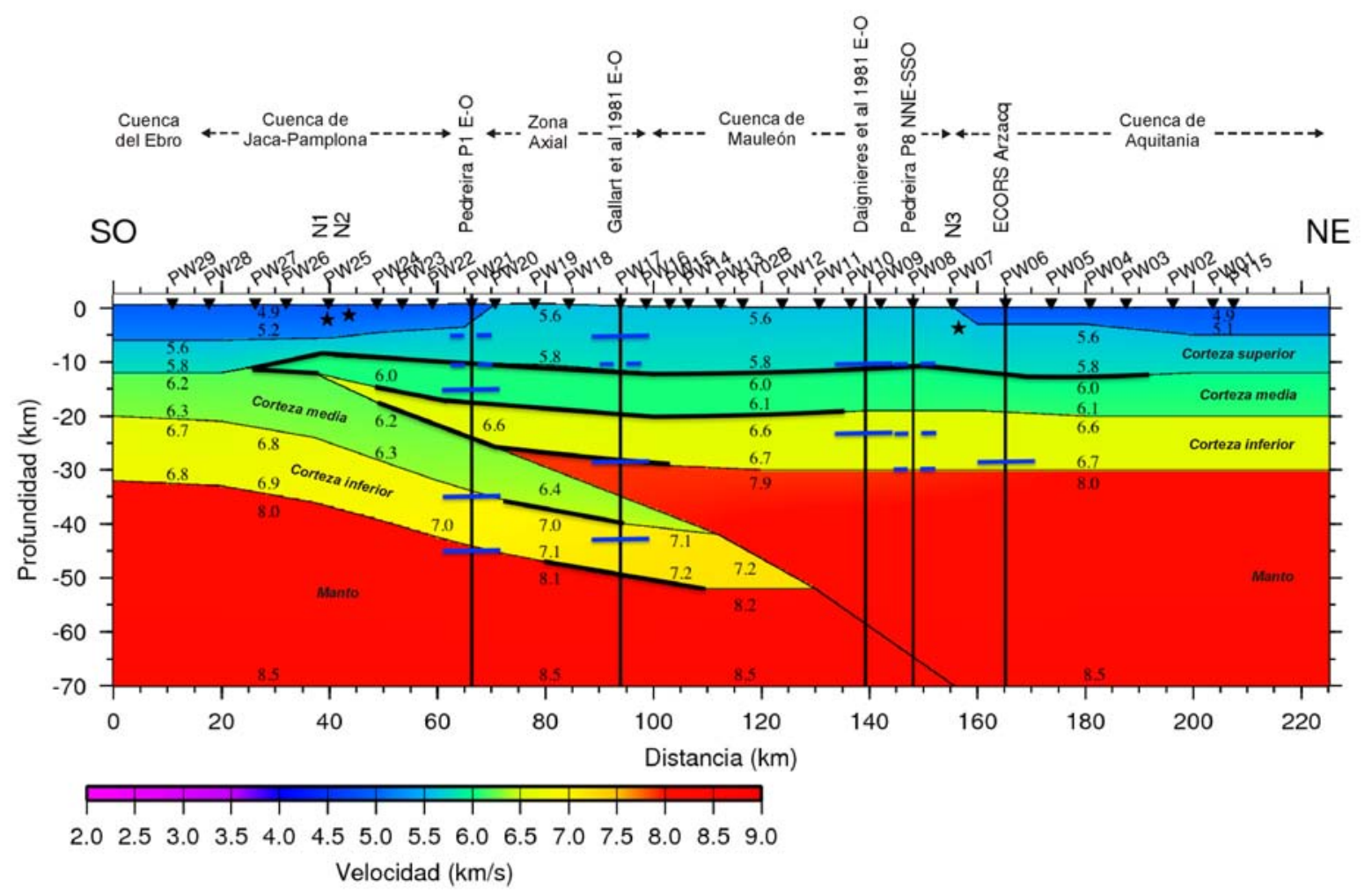

Figura 12. Modelo de velocidad-profundidad obtenido para el perfil Navarra de la zona occidental de los Pirineos. Las estrellas negras muestran la posición de los diferentes sismos. En negro aparecen resaltados los horizontes que han sido acotados por los datos de este trabajo. En azul se marcan los horizontes que han sido acotados por otros autores en los puntos de corte con otros perfiles. Las líneas verticales negras indican la zona de corte entre este perfil y los realizados por otros autores en las proximidades de esta área de estudio. Figure 12. Velocity-depth model obtained for the Navarra profile in the western Pyrenees. Black stars show the position of the different earthquakes. Bold black lines highlight the crustal levels fitted in this work. Bold blue lines mark the horizons delimited by other authors in this area. Vertical black lines show cutting the sector between this profile and those obtained by previous studies.

una corteza tipo varisca no deformada. La profundidad del Moho Ibérico, sin embargo, aumenta progresivamente hacia el $\mathrm{N}$ a medida que se alcanza la Zona Axial de los Pirineos, incrementándose desde unos 35 $\mathrm{km}$ en el extremo más meridional del perfil hasta superar los $50 \mathrm{~km}$ en el área central de la cordillera, donde la raíz cortical alcanza su máximo desarrollo (Fig. 12). Sobre el modelo final se han señalado los puntos de corte entre este perfil y los realizados por otros autores, delimitando con una línea negra más gruesa diferentes horizontes corticales acotados en este estudio $y$, en azul, los límites establecidos en estudios anteriores.

\section{Discusión}

En este trabajo realizado en la cordillera pirenaica se ha demostrado la viabilidad, aunque con limitaciones, de obtener información precisa sobre la estruc- tura de la corteza, mediante la modelización de tres perfiles sísmicos de gran ángulo, cuya fuente sísmica fueron terremotos registrados en redes temporales desplegadas para registrar telesismos. Efectivamente, los modelos no sólo permitieron establecer las características de la estructura más superficial, sino que fue posible obtener una imagen detallada de la geometría de las estructuras más profundas resultantes del proceso de colisión continental entra la placa Europea y la placa lbérica durante la orogenia Alpina.

\section{Sector oriental de los Pirineos}

Los datos extraídos de los tres sismos empleados en el desarrollo del modelo del perfil E-O Cataluña 1 (Fig. 6 ), permitieron definir las superficies que limitan la corteza media de la inferior y ésta del manto, en la mitad oriental del modelo. En esta zona se obtuvieron 
las geometrías y profundidades de ambas superficies, que son compatibles con las obtenidas en los estudios precedentes. En cambio, los datos registrados no aportaron información que permita prolongar estos niveles corticales hacia el sector occidental del modelo ni tampoco diferenciar la corteza superior de la media. El engrosamiento cortical en el sector occidental, reflejado en el perfil Cataluña 1, se incorporó en la modelización en base a los resultados más recientes de otros autores (Díaz et al., 2016; 2018), de forma que la base de la corteza se representó a una profundidad de más de $40 \mathrm{~km}$ en el extremo occidental, mientras que la potencia cortical en el extremo oriental se reduce a unos $25 \mathrm{~km}$. En el caso del perfil $\mathrm{N}-\mathrm{S}$ Cataluña 2 (Fig. 8) se aprovecharon dos terremotos situados aproximadamente en el centro de la línea. En este caso sólo se pudo tener control del límite corteza media-corteza inferior en algunos sectores discretos, situándolo a unos $20 \mathrm{~km}$ de profundidad. Al igual que en el perfil anterior, tampoco se pudo detectar el límite corteza superior - corteza media, y la morfología del Moho fue tomada de los datos de estudios precedentes de esta zona oriental de los Pirineos (Gallart et al., 1980; 1981; Daignieres et al., 1981; Díaz et al., 2016; 2018). La imagen global muestra un engrosamiento cortical en el centro del orógeno por el desarrollo de la raíz cortical pirenaica, visible en el extremo $O$ del perfil Cataluña 1 y la zona central del perfil Cataluña 2. Por otra parte, el perfil Cataluña 1 refleja un adelgazamiento cortical progresivo desde las zonas centrales de la cordillera al oeste hacia el margen continental ibérico al este.

Hay que destacar que la localización al azar de las fuentes sísmicas, por tratarse de terremotos, y la insuficiente apertura de los dos perfiles, han condicionado los resultados finales, siendo un factor limitante para la modelización. La apertura, entendida como la distancia entre el sismo y el extremo del perfil, no ha sido suficiente como para registrar las fases profundas que hubiesen permitido definir con mayor precisión la geometría de la base de la corteza o las velocidades de la parte más somera del manto, sobre todo en las zonas donde la corteza está más engrosada. Sólo el terremoto $\mathrm{C} 3$, situado en el extremo más oriental del perfil E-O y en la zona más delgada del modelo, disponía de estaciones situadas a offsets adecuados para permitir registrar con claridad fases profundas $\mathrm{PcP}$ y $\mathrm{PmP}$, pero en ningún caso se registró fases Pn. Aún con estas limitaciones, los resultados derivados de los ajustes de las fases profundas registradas en C3 son compatibles con los resultados obtenidos mediante funciones receptoras a lo largo del mismo perfil Pyrope E-O (Díaz et al., 2018), y son también compatibles con el adelgazamiento cortical en el extremo oriental de la cordillera pirenaica (Gallart et al., 1981; Díaz et al., 2016) quedando patente, de este modo, la compatibilidad de los resultados empleando dos técnicas tan distintas. Los datos adquiridos no han permitido obtener un modelo muy detallado en el sector más superficial de la corteza, no siendo posible identificar la cuenca del Ebro ni la cuenca de Aquitania, del mismo modo que tampoco se pudo hacer una distinción entre la corteza superior $y$ media.

En cuanto al rango de velocidades obtenido en estos modelos, es coherente con los propuestos por Gallart et al. (1980; 1981) y Daignières et al. (1981) en este sector de los Pirineos en la medida que es posible compararlos, ya que no ha sido posible discriminar en ninguno de estos dos modelos ni las cuencas sedimentarias ni el límite entre la corteza superior y la corteza media. Aun así, la primera capa de los modelos Cataluña tiene una velocidad media de unos 6.1 $\mathrm{km} / \mathrm{s}$, que correspondería a la velocidad promedio de la corteza superior más la corteza media de los perfiles modelizados por loa autores precedentes.

\section{Sector occidental de los Pirineos}

El perfil Navarra, el más occidental de los analizados, muestra una estructura compleja, con un importante engrosamiento cortical en el sector central de la línea, en la Zona Axial de los Pirineos, derivado de la colisión entre la placa Ibérica y la placa Europea. Este estudio ha permitido obtener un modelo en el que ha sido posible distinguir los diferentes niveles corticales, aportando información sobre su: potencia, profundidad, posición y velocidad, incluyendo la profundidad del Moho en varios sectores de ambas placas. Este modelo presenta una corteza superior, en la que se han diferenciado sendas cuencas en cada extremo del perfil. La cuenca meridional corresponde al conjunto formado por la cuenca del Ebro y la cuenca de Jaca-Pamplona, y la cuenca septentrional a la de Aquitania. Estas cuencas tienen una potencia de unos $5 \mathrm{~km}$ aproximadamente, decreciendo hacia el centro del perfil, es decir, hacia los materiales mesozoicos y paleozoicos de la Zona Axial.

La estructura profunda es más compleja. Se han diferenciado las cortezas media e inferior Europea e Ibérica, estando las cortezas media e inferior de la placa Ibérica inclinadas hacia el $\mathrm{N}$ y subduciendo bajo las correspondientes de la placa Europea, debido a la indentación hacia el $\mathrm{S}$ de la última. La profundidad máxima del Moho lbérico se ha localizado a unos 50 $\mathrm{km}$ mientras que el Moho Europeo se ha acotado a unos $30 \mathrm{~km}$. Los resultados obtenidos para este 
modelo son compatibles con los obtenidos por otros experimentos de sísmica de reflexión y de refracción de gran ángulo realizados en este sector de la zona de estudio (Gallart et al., 1981; Daignières et al., 1981; Pedreira et al., 2003) (Fig. 12). Las distintas capas identificadas en este trabajo muestran unos rangos de velocidad coherentes con los propuestos por otros autores (Gallart et al., 1981; Daignières et al., 1981; Pedreira et al., 2003; Díaz et al., 2012), es decir, una corteza superior de unos $5.7 \mathrm{~km} / \mathrm{s}$ en los que es posible identificar sendas cuencas con velocidad de 5.0 $\mathrm{km} / \mathrm{s}$, la corteza media de $6.1 \mathrm{~km} / \mathrm{s}$ y la corteza inferior de unos $6.7 \mathrm{~km} / \mathrm{s}$, aumentando la velocidad de la corteza media e inferior en la placa lbérica a medida que profundiza al subducir bajo la placa Europea.

Por lo que respecta a la estructura en detalle de la parte sur del perfil, las profundidades de la base y el techo de la corteza inferior lbérica acotadas para el modelo de Navarra son compatibles con las obtenidas por Pedreira et al., (2003) en su perfil 1. Los datos registrados en los terremotos $\mathrm{N} 1$ y N2 permiten definir estas mismas superficies buzando hacia el norte, con una pendiente que, extrapolada hacia el sur, encajaría correctamente con los valores del perfil 1 de este autor. El perfil E-O de Gallart et al. (1981) cruza el perfil de este estudio a la altura de la estación PW17, esbozando en esta zona un Moho a dos alturas, pasando de unos $30 \mathrm{~km}$ a unos $43 \mathrm{~km}$ de profundidad, con un salto brusco en forma de escalón justo en la zona de corte con el perfil de Navarra. Los datos del presente estudio permiten definir con exactitud la base de la corteza Europea a unos $27-29 \mathrm{~km}$ de profundidad, coincidiendo con el Moho situado a $30 \mathrm{~km}$ identificado por Gallart et al. (1981). En cambio, el nivel interpretado por estos últimos como Moho a 43 $\mathrm{km}$ de profundidad, coincidiría con el techo de la corteza inferior lbérica definido tanto en el modelo de Navarra como en el modelo de Pedreira et al., 2003. En lo que respecta a los datos obtenidos a partir del terremoto N3, situado $22 \mathrm{~km}$ al este de la línea, su modelización da lugar, debido a la oblicuidad, a una sección aparente de la estructura respecto a la observada por N1 y N2 por lo que la información de esta parte profunda del modelo fue desechada en la obtención del modelo final (Antonio-Vigil, 2017).

En cuanto a la estructura de la parte norte del perfil, las cortezas media e inferior Europeas aparecen subhorizontales y se acuñan hacia el $\mathrm{S}$ en la zona de la indentación cortical. En la zona alejada de la indentación, el perfil E-O de Daignières et al. (1981) sitúa el Moho a aproximadamente $23 \mathrm{~km}$ de profundidad entre las estaciones PW09 y PW10. Sin embargo, el modelo de Navarra localiza el techo de la corteza inferior Europea, mediante los datos de los tres terremo- tos, a aproximadamente $20 \mathrm{~km}$ de profundidad en una zona muy próxima al punto de corte con el perfil de Daignières et al. (1981). La identificación en nuestro modelo de esta discontinuidad como el techo de la corteza inferior, en lugar de su base (o Moho), es compatible con la interpretación que hacen Pedreira et al., (2003) en su modelo del perfil 8 que cruza el perfil de Navarra a la altura de PW08 (Fig. 12). Este autor también coincide en situar el Moho europeo a $30 \mathrm{~km}$ de profundidad, valor que es a su vez compatible con los observados en el perfil ECORS-Arzacq (Daignières et al., 1994; Teixell, 1998). En la región septentrional del modelo de Navarra, al no aportar el ensamblaje de $\mathrm{N} 3$ fases $\mathrm{PmP}_{\mathrm{E}}$ que permitan acotar el Moho europeo, se ha trazado éste dando por válido el valor de $30 \mathrm{~km}$ de profundidad de estudios anteriores, incluyendo el perfil ECORS-Arzacq (Daignières et al., 1994; Teixell, 1998; Pedreira, 2004) (Fig. 12).

El perfil Pyrope Navarra analizado en este estudio también ha sido estudiado aplicando las técnicas para las cuales fue diseñado: funciones receptoras por Chevrot et al. (2015) y métodos tomográficos de inversión de onda para fases telesísmicas por Wang et al. (2016). En ambos casos se propone un modelo que difiere significativamente del obtenido en este trabajo. La principal diferencia entre los anteriores estudios y el actual, reside en la presencia de una intrusión mantélica en la zona central del perfil (Wang et al., 2016), no identificada en este trabajo, ni en trabajos previos. Esta intrusión del manto, también propuesta recientemente por Pedrera et al. (2017) mediante modelización gravimétrica y magnética, llega a alcanzar los $10 \mathrm{~km}$ de profundidad en su zona más superficial, lo que provoca un adelgazamiento local sustancial de la corteza.

Con el fin de comprobar si un modelo de estas características es compatible con los datos de gran ángulo de este estudio, se llevaron a cabo varias pruebas generando familias de modelos análogos, más o menos complejos, en los que se incluyó una intrusión mantélica en la zona de indentación similar a la propuesta por Wang et al. (2016). Sin embargo, en ningún caso se logró ajustar satisfactoriamente las fases profundas registradas en los tres terremotos analizados en este estudio, mediante modelos de capas que incluyeran dicha anomalía de alta velocidad (Antonio-Vigil, 2017). Esto no implica que se pueda descartar de facto un modelo de este tipo, simplemente indica que con los datos disponibles y las técnicas de refracción y reflexión gran ángulo empleadas en este trabajo no ha sido posible llegar a una solución satisfactoria que permita corroborar o descartar la intrusión mantélica. Las técnicas empleadas para la obtención de dichos modelos y utilizar como 
fuente telesismos, implican diferencias de orden con este estudio, en el que se analizan sismos localesregionales; distintos rangos de frecuencias empleadas, diferencias en el ángulo de incidencia de las señales analizadas e incluso en el tipo de onda (S o $\mathrm{P})$. Los rayos de los telesismos tienen un ángulo de incidencia prácticamente normal a la superficie, muestreando áreas que están prácticamente en la vertical de la estación receptora y son por tanto sensibles a anomalías muy focalizadas lateralmente. Además, los métodos tomográficos de ondas de cuerpo tienen muy buena resolución lateral pero su resolución vertical es más limitada, pudiendo aparecer en algunos casos las anomalías elongadas verticalmente. En cambio, los rayos de los terremotos locales/regionales empleados en este trabajo pueden tener ángulos de incidencia muy variados, barriendo todo el modelo hasta con trayectorias prácticamente horizontales. Por lo tanto, en este caso, al ajustar los tiempos de trayecto de sólo 3 fuentes, la resolución lateral puede ser inferior a la de los modelos tomográficos, ya que las anomalías de velocidad pueden quedar promediadas a lo largo de grandes trayectorias. Finalmente, hay que remarcar que Wang et al. (2016) obtienen modelos de Vs y Vp, siendo el modelo de $V$ s el que mejor muestra esa anomalía de alta velocidad que ellos han identificado como una intrusión mantélica, sin embargo, el modelo del presente trabajo es un modelo de velocidad de ondas $\mathrm{P}$. De hecho, en su modelo de ondas $\mathrm{P}$, esta anomalía aparece más difusa. Aunque en un principio cabría esperar que la resolución de las ondas $\mathrm{P}$ fuera mejor que la de las ondas $S$, pues éstas tienen frecuencias menores, los métodos tomográficos de inversión de forma de onda trabajan mejor a bajas frecuencias, explicando así la mejor resolución de los modelos Vs. Los terremotos locales proporcionan señales de más alta frecuencia que los telesismos, por lo tanto, la resolución debería ser mayor, pero en el caso del presente trabajo, al disponer de sólo tres fuentes sísmicas, predominan en la resolución otros aspectos como los mencionados anteriormente.

\section{Conclusiones}

En el presente trabajo, se ha realizado un estudio de la estructura cortical pirenaica mediante técnicas de sísmica de reflexión y refracción de gran ángulo. En él se presentan un total de tres modelos, dos en los Pirineos orientales y un tercero en los Pirineos occidentales. Estos modelos se han obtenido empleando como fuentes sísmicas seis terremotos locales/regionales registrados entre los años 2011 y 2013 en la red sísmica temporal Pyrope y las estaciones permanentes del IGN, IGCG y RéNaSS.

El perfil Cataluña 1 registrado en dirección E-O en el sector oriental de los pirineos ha permitido modelizar segmentos discretos del techo de la corteza inferior y de la superficie del Moho en la zona del adelgazamiento cortical de la cordillera entre la raíz cortical y el margen continental. A pesar de que en este perfil no existían puntos de corte con modelos realizados en estudios previos, la profundidad del Moho es compatible con los estudios previos cercanos (Díaz et al., 2016) y con la obtenida en estudios recientes, en las que se han empleado técnicas de funciones receptoras de telesismos a lo largo de el mismo perfil (Díaz et al., 2018).

El perfil Cataluña 2 registrado en dirección N-S aporta una escasa información sobre la estructura de la cordillera, acotando únicamente algunos segmentos del techo de la corteza inferior. Se ha podido correlacionar el techo de la corteza inferior identificado en ambos perfiles con el conversor intracortical visible a $20 \mathrm{~km}$ de profundidad en la imagen de la pseudomigración de las funciones receptoras telesísmicas registrado por Díaz et al. (2018).

El perfil Navarra, registrado en la dirección NE-SO, transversal a los Pirineos occidentales, aportó una gran cantidad de información sobre la estructura cortical de la cordillera. En él ha sido posible identificar tanto las cuencas del Ebro y de Arzacq como la estructura general del orógeno con la indentación de la placa Europea hacia el S en la placa Ibérica y la subducción de ésta hacia el $\mathrm{N}$ formado una raíz cortical por duplicación de las cortezas.

Los datos adquiridos han permitido modelizar una gran parte de los límites corteza superior-media y corteza media-inferior en la zona correspondiente a la corteza Europea. Sin embargo, el Moho de la placa Europea ha sido muestreado sólo en una pequeña región en la zona central del modelo a unos $30 \mathrm{~km}$ de profundidad. Esto es concordante con las profundidades del Moho propuestas por Gallart et al. (1981), Pedreira (2004) y Teixell (1998).

Ha sido posible identificar un segmento del límite corteza media-inferior de la placa lbérica buzando hacia el N. También se ha acotado parte del Moho de la placa Ibérica, en su extremo más septentrional, a una profundidad de $45-50 \mathrm{~km}$, coincidente con los modelos previos sobre el engrosamiento cortical producido por el choque de las placas Ibérica y Europea. Esta profundidad del Moho es superior la propuesta porTeixell (1998) y Gallart et al. (1981) de unos 40 km, sin embargo, es compatible con las propuestas por Pedreira et al. (2003), Chevrot et al. (2015; 2018), Wang et al. (2016) y Díaz et al. (2012; 2016). 
Debido a la excesiva separación lateral del terremoto N3 de la línea de estaciones, no ha sido posible modelizar simultáneamente los registros de los tres terremotos en la parte correspondiente a las cortezas media e inferior lbérica y el sector más profundo del modelo se ha construido únicamente con los datos de los terremotos N1 y N2.

Tras los resultados obtenidos, que están en concordancia y complementan los modelos corticales previos que no incluyen intrusiones mantélicas en los niveles más superficiales de la corteza, se ha demostrado que desde el punto de vista metodológico el empleo de una fuente sísmica natural tiene gran utilidad para la construcción de modelos corticales de sísmica de refracción gran ángulo, pese a las limitaciones que a priori puede conllevar debido a la distribución al azar tanto de la localización del foco como del tiempo origen. Por lo tanto, en determinadas circunstancias es posible aprovechar los registros de terremotos locales-regionales adquiridos por una red temporal de estaciones sísmicas desplegada con otros fines como el registro de telesismos.

\section{Agradecimientos}

Este trabajo ha sido financiado por el Ministerio de Economía y Competividad, Proyecto MISTERIOS (CGL2013-48601-C2-R) y por el Grupo de Calidad de la Generalitat (2017 SGR1022). El proyecto PYROPE fue financiado por la Agencia Francesa de Investigación ANR blanc Programme (ANR-09-BLAN-0229). Los datos sísmicos de las redes temporales se pueden descargar del nodo RESIF EIDA (http:/portal.resif.fr). Los autores agradecen los datos suministrados por la Red Sísmica Española (IGN), la Red Sísmica Catalana (ICGC) (https://doi.org/10.7914/SN/CA) y la Red Sísmica Francesa (RESIF) (https://doi.org/10.15778/ RESIF.FR). A. Antonio-Vigil disfrutó de dos estancias en el ICTJA, producto del convenio de colaboración entre la Universidad de Oviedo y el CSIC. Agradecemos al Laboratorio de Sísmica del ICTJACSIC (http://labsis.ictja.csic.es) el préstamo de las estaciones símicas empleadas en las redes temporales. Los autores quieren agradecer los comentarios y contribuciones hechas a este manuscrito por Jesús García Senz y dos revisores anónimos.

\section{Referencias}

Anadón, P. y Roca, E. (1996). Geological setting of the Tertiary basins of Northeast Spain. En: Friend, P. F. y Dabrio, C. J. (Eds), Tertiary basins of Spain. The stratig- raphy record of crustal kinematics. Cambridge University Press, 43-48.

Antonio-Vigil, A. (2017). Estudio cortical del Pirineo mediante refracción y reflexión de gran ángulo utilizando terremotos como fuente sísmica natural. Trabajo Final de Máster, Universidad de Oviedo. http://hdl.handle.net/ $10651 / 42889$.

Buis, M. G. y Cugni, P. (1978). Les poudingues de Palassou entre l'Ariège et le Doutouyre (Pyrénées Ariégeoises). Bulletin de la Société d'Historie Natirelle de Toulouse, $114,212-236$.

Chevrot, S., Sylvander, M., Díaz, J., Martin, R., Mouthereau, F., Manatschal, G., Masini, E,m Calassou, S., Grimaud, F., Pauchet, H. y Ruiz, M. (2018) The non-cylindrical crustal architecture of the Pyreness. Scientific. Reports, 8:9591. doi: 10.1038/s41598-018-27889-x

Chevrot, S., Sylvander, M., Díaz, J., Ruiz, M., y Paul, A., and the PYROPE Working Group. (2015). The Pyrenean architecture as revealed by teleseismic P-to-S converted waves recorded along two dense transect: Geophysical Journal International, 200, 1096-1107, doi:10.1093/ gji/ggu400.

Coney. P. J., Muñoz, J. A., McClay, K. R. y Evenchick, C. A. (1996). Syntectonic burial and post-tectonic exhumation of the southern Pyrenees foreland fold-thrust belt. Geological Society. London, 153-9,16.

Daignières, M., Gallart, J. y Banda, E. (1981). Lateral variation of the crust in the North Pyrenean Zone. Ann. Géophysique, 3, 435-456.

Daignières, M., Séguret, M., Specht, M. y ECORS Team. (1994). The Arzacq-Western Pyrenees ECORS Deep Seismic Profile. En: Mascle, A (Ed.), Hydrocarbon and petroleum geology of France. Springer, 199-208.

De Sitter, L. U. (1956). Structural Geology (International serie in the Earth sciences). McGraw-Hill 522 pp.

Déramond, J., Graham, R. H., Hossack, J. R., Bay, P. y Crouzet, G. (1985). Nouveau modèle de la Chaîne des Pyrénées. Comptes Rendus de l'Académie des Sciences Série II, 301 (16), 1213-1216.

Déramond, J., Souquet, P., Fondecave-Wallez, M. J. y Spetch, M. (1993). Relationship between thrust tectonics and sequence stratigraphy surfaces in foredeps: model and examples from the Pyrenees (Cretaceous-Eocene, France, Spain). En: Williams, G. D. y Dobb, A (Eds.), Tectonics and seismic sequence stratigraphy. Geological Society London, Special Publications 71, 193-219.

Díaz, J., y Gallart, J. (2009). Crustal structure beneath the Iberian Peninsula and surrounding waters: a new compilation of Deep seismic sounding results. Physics of the Earth and Planetary Interiors. 173, 181-190. http://dx.doi.org/10.1016/j.pepi.2008.11.008.

Díaz, J., Gallart, J. y Carbonell, R. (2016). Moho topography beneath the Iberian-Western Mediterranean region mapped from controlled-source and natural seismicity surveys. Tectonophysics, 692, 74-85. doi: 10.1016/j.tecto.216.08.023.

Díaz, J. Pedreira, D., Ruiz, M., Pulgar, J.A. y Gallart, J. (2012). Mapping the indentation between the Iberian and Eurasian plates beneath the Western Pyrenees/Eastern Cantabrian Mountains from receiver function analysis. 
Tectonophysics, 570-571, 114-122. http://dx.doi.org/ 10.1016/j.tecto.2012.07.005

Díaz, J., Vergés, J., Chevrot, S., Antonio-Vigil, A., Ruiz, M., Sylvander, M. y Gallart, J., (2018). Mapping the crustal structure beneath the eastern Pyrenees. Tectonophysics, 744, 296-309. doi: 10.1016/ j.tecto.2018.07.011

Dumont, T., Replumaz, A., Rouméjon, S., Briais, A., Rigo, A. y Bouillin, J. P. (2015). Microseismicity of the Béarn range: Reactivation of inversion and collision structures at the northern edge of the Iberian plate. Tectonics, 34, 934-950. doi: 10.1002/2014TC003816.

Fischer, M. W. (1984). Thrust Tectonics in the North Pyrenees. Journal of Structural Geology, 6 (6), 721-726.

Gallart, J., Banda, E. y Daignières, M. (1981). Crustal structure of the Paleozoic Axial Zone of the Pyrenees and transition to the North Pyrenean Zone. Annales Géophysique, 3, 457-480.

Gallart, J., Daignières, M., Banda, E., Suriñach, E. y Hirn, A. (1980). The eastern Pyrenean domain: lateral variation at crust-mantle level. Annales Géophysique, 2, 141-158.

Gallastegui, J., Pulgar, J.A., y Gallart, J. (2016). Alpine tectonic wedging and crustal delamination in the Cantabrian Mountains (NW Spain). Solid Earth, 7 (4), 1043.1057. Doi: 10.5194/se-7-1043-2016.

Goldstein, P. y Minner, L. (1996). SAC2000: Seismic Signal Processing and Analysis Tools For the 21st Century. Seismological Research Letterst, 67, 39.

Goldstein, P., Dodge, D., Firpo, M. y Minner, L. (2003). SAC2000: Signal processing and analysis tools for seismologists and engineers. En: Lee, W. H. K., Kanamori, $\mathrm{H}$., Jennings, P. C y Kisslinger, C., "The IASPEI International Handbook of Earthquake and Engineering Seismology", Academic Press, London, 1613-1614. http://dx.doi.org/10.1016/S0074-6142(03)80284-X

IGME. (1990). Documentos sobre la Geología del subsuelo de España. Tomo: VI: Ebro-Pirineos. Instituto Geológico y Minero de España (IGME), Serv. Public., Madrid. 45 pp.

Institut Cartogràfic i Geològic de Catalunya (2000). Catalan Seismic Network. International Federation of Digital Seismograph Networks. Other/Seismic Network. doi:10.7914/SN/CA.

Lahr, J. C. (1999). A computer program for determining local earthquake hypocentral parameters, magnitude and first-motion pattern. U. S. Geol. Survey Open-file report, 99-23.

Lahr, J. C. y Snoke J. A. (2003). The HYPOELLIPSE earthquake location program. En: Lee, W. H. K., Kanamori, H., Jennings, P. C. y Kisslinger, C (Eds) The IASPEI International Handbook of Earthquake and Engineering Seismology, Vol. 81B. Academic Press, London, 16171618.

Lee, W. H y Lahr, J. C. (1975). HYPO71 (revised): A computer program for determinig hypocenters, magnitudes and first motion pattern of local earthquakes. U. S. Geological Survey Open File report, 75-311, 116 pp.

Mattauer, M. (1968): Les traits structuraux essentiels de la chaîne Pyrénéenne. Rev. Géogr. Phy. Géol. Dyn, 10, 312.

Matte, Ph. (1991). Accretionary history and crustal evolution of the Variscan belt in Western Europe. Tectonophysics, 196, 309-337.
Muñoz, J. A. (1992). Evolution of a continental collision belt: ECORS-Pyrenees crustal balanced cross-section. En: McKlay, K. (Ed.), Thrust Tectonics, Chapman \& Hall, London, 234-246.

Palomeras, I., Carbonell, R., Flecha, I., Simancas, F., Ayarza, P., Matas, J., Martínez Poyatos, D., Azor, A., GonzálezLodeiro, F. y Pérez-Estaún, A. (2009). Nature of the lithosphere across the Variscan orogen of SW Iberian: Dense wide-angle seismic reflection data. Journal of Geophysical Research, 114, B02302. doi: 10.1029/ 2007JB005050

Pedreira, D. (2004). Estructura cortical de la zona de transición entre los Pirineos y la Cordillera Cantábrica. Tesis Doctoral (Inédita), Universidad de Oviedo. España. 343 pp.

Pedreira, D., Afonso, J.C., Pulgar, J. A., Gallastegui, J., Carballo, A., Fernández, M., García-Castellanos, D., Jiménez-Munt, I., Sempirich, J., García-Moreno, O. (2015). Geophysical petrological modeling of the lithosphere beneath the Cantabrian Mountains and NorthIberian margin: geodynamic implications. Lithos 230, 46-68. http://dx.doi.org/10.1016/j.lithos.2015.04.018.

Pedreira, D., Pulgar, J.A., Gallart, J. y Díaz, J. (2003). Seismic evidence of Alpine crustal thickening and wedging from the western Pyrenees to the Cantabrian Mountains (north Iberia). Journal of Geophysical Research, 108 (B4), 2204. http://dx.doi.org/10.1029/2001JB001667.

Pedreira, D., Pulgar, J.A., Gallart, J., Torné,M. (2007). Threedimensional gravity and magnetic modeling of crustal indentation and wedging in the western Pyrenees Cantabrian Mountains. Journal of Geophysical Research. 112, B12405. http://dx.doi.org/10.1029/2007 JB005021.

Pedrera, A., García-Senz, J., Ayala, C., Ruiz-Constanza, A., Rodríguez-Fernández, LR., Robardo, A. y González Menéndez, L. (2017) Reconstruction of the Exhumed Mantle Across the North Iberian Margin by Crustal Scale 3 D Gravity Inversion and Geological Cross Section. Tectonics, 36, 3155-3177 pp. doi: 10.1002/2017TC004716.

Puigdefábregas, C. (1975) La sedimentación molásica en la cuenca de Jaca. Pirineos, 104: 1-188.

Pulgar, J.A., Gallart, J., Fernández-Viejo, G., Pérez-Estaún, A., Álvarez-Marrón, J. y ESCIN Group (1996). Seismic image of the Cantabrian Mountains in the western extension of the Pyrenees from integrated ESCIN reflection and refraction data. Tectonophysics, 264, 1-19.

RESIF. (1995). RESIF-RLBP French Broad-band network, RESIF-RAP strong motion network and other seismic stations in metropolitan France. RESIF - Réseau Sismologique et géodésique Français. doi: 10.15778/RESIF.FR.

Souriau, A. y Pauchet, H. (1998). A new synthesis os Pyrenean seismicity and its tectonic implications. Tectonophysics, 290, 221-244.

Souriau, A., Sylvander, M., Rigo, A., Fels, J. F., Douchain, J. M. y Ponsolles, C. (2001). Sismotectonique des Pyrenees: Principales constraintes sismologiques. Bulletin Socciété Géologique France, 172, N1, 25-39.

Teixell, A. (1998). Crustal structure and orogenic material budget in the west central Pyrenees. Tectonics, 17 (3), 395-406. 
Teixell, A. y García-Sansegundo, J. (1995) Estructura del sector central de la Cuenca de Jaca (Pirineos meridionales). Revista de laSociedad Geológica de España, 8 (3), 215-228.

Vergés, J., Millán, H., Roca, E., Múñoz, J. A., Marzo, M., Cirés, J., Den Bezemer, T., Zoetemeijer, R. y Cloeting, S. (1995). Eastern Pyrennes and related forelan basin: pre-, syn-, and post-collisional crustal-scale cross-section. Marine and Petroleum Geology, 12 (8), 893-815.

Wang, Y., Chevrot, S., Monteiller, V., Komatitsch, D., Mouthereau, F., Manatschal, G., Sylvander, M., Díaz, J., Ruiz, M., Grimaud, F., Benahmed, S., Pauchet, H. y Martin, R. (2016). The deep roots of the western Pyrenees revealed by full waveform inversion of teleseismic P waves. Geology, 44 (6), 475-478.
Williams, G. D. (1985). Thrust Tectonics in the South Central Pyrenees. Journal of Structural Geology, 7 (1), 11-17.

Zelt, C. A. (1999). Modelling strategies and model assessment for wide-angle seismic traveltime data. doi: 10.1130/637812.1. Geophysical Journal International, V. 139. I. 1, 1, Pp. 183-204, doi: 10.1046/j.1365-246X.1999. 00934.x

Zelt, C.A. y Ellis, R.M. (1988). Practical and efficient ray tracing in two-dimensional media for rapid traveltime and amplitude forward modelling, Canadian Journal of Exploration Geophysics, Vol. 24, N.1, 16-31.

Zelt, C.A. y Smith, R.B. (1992). Seismic traveltime inversion for 2-D crustal velocity structure, Geophysical Journal International, 108, 16-34.

Recibido: septiembre 2018

Revisado: febrero 2019

Aceptado: abril 2019

Publicado: septiembre 2019 